\title{
Mitochondrial dysfunction in cholestatic liver diseases
}

\author{
Alessandro Arduini ${ }^{1}$, Gaetano Serviddio ${ }^{2}$, Ana M. Tormos ${ }^{1}$, Maria Monsalve ${ }^{3}$, Juan Sastre ${ }^{1}$ \\ ${ }^{I}$ Department of Physiology, School of Pharmacy, University of Valencia, Valencia, Spain, ${ }^{2}$ Department of Medical and \\ Occupational Sciences, University of Foggia, Foggia, Italy, ${ }^{3}$ Centro Nacional de Investigaciones Cardiovasculares, Consejo \\ Superior de Investigaciones Cientificas, CNIC, CSIC, Madrid, Spain
}

\section{TABLE OF CONTENTS}

1. Abstract

2. Cholestatic liver diseases

3. Impairment of mitochondrial function in cholestatic liver disease

4. Mitochondrial biogenesis in cholestatic liver disease

5. Mitochondrial-mediated apoptosis in cholestatic liver disease

4.1. General aspects

4.2. Bile acids promote apoptosis in liver

4.3. Apoptosis in liver cholestasis: time course and mechanisms

4.4. Anti-apoptotic response to cholestatic injury

6. Mitochondrial oxidative stress in cholestatic liver disease

7. Dual role of inflammation in chronic cholestasis

8. Cholestatic liver disease as a secondary mitochondriopathy

9. Mitochondria as putative targets for therapeutic intervention in cholestasis

10. Concluding remarks

11. References

\section{ABSTRACT}

Cholestatic liver diseases are characterized by blockade of bile flow from the liver to the intestine, and accumulation of hydrophobic bile acids in the liver and plasma. As a consequence an inflammatory response evolves associated with increased apoptosis, oxidative stress, and eventually fibrosis. Cholestasis is associated with profound metabolic changes, alterations in the mitochondrial function, decreased fatty acid oxidation, and increased glycolisis. Mitochondria play a central role in the development of this liver disease because they mediate death receptor signaling - triggered by inflammatory cytokines or bile acids - and contribute to oxidative damage, metabolic disorder, and onset of fibrosis. During the pathogenesis of biliary cirrhosis mitochondria's need for renewal is hampered by a blunted mitochondrial biogenesis. Lack of stimulation of mitochondrial renewal helps to explain mitochondrial impairment in long-term cholestasis. The marked depletion of mitochondrial DNA and occurrence of mitochondrial DNA deletions are probably relevant contributors to the progression of this severe disease. All these findings certainly support the consideration of long-term cholestasis as a secondary mitochondrial hepatopathy.

\section{CHOLESTATIC LIVER DISEASES}

Cholestasis literally means "standing still of bile", and is defined as any condition that causes retention and accumulation of potentially toxic bile acids in the liver and the systemic circulation 1. Cholestasis can be triggered by different causes, such as inflammation, viral infection, autoimmune diseases, gallstones, or tumors of the pancreas, liver or biliary tree. The origin of the hepatic damage can generally be hepatocellular - ascribed to a functional defect in bile formation mainly due to genetic mutations - or ductular/ductal (referred as obstructive jaundice) - caused by an impairment of bile secretion at the level of the bile ducts $-2-4$.

Cholestasis is responsible for severe biochemical and structural alterations of several organs, being the liver the most affected. Chronic cholestasis results in profound changes in liver architecture - fibrosis and increase in bile ductules - 5, 6, morphology - hepatomegaly and appearance of regenerative nodules -6 , and physiology - decreased enterohepatic circulation of bile acids and synthesis of albumin, portal hypertension - 6, 7. From a biochemical point of view, in cholestasis there is a shift in the mechanisms of energy production, since an alteration of mitochondrial function in the liver is associated with an increase in the glycolitic activity to cope with energy needs.

Experimentally, cholestasis is usually studied in rodents, but also in rabbits and dogs, by the use of surgical intervention of common bile duct ligation (BDL or CBDL) 8, 9. This technique simulates an extrahepatic cholestasis, as could occur because of gallstones or tumors, and causes accumulation of bile acids and other compounds in the liver and in plasma. In order to discriminate systemic effects (e.g. inflammatory mediators, hormonal regulation) from organ specific effects of cholestasis (e.g. mechanisms of apoptosis), ligation of just one bile duct (partial bile duct ligation, PBDL) can be performed 10, 11. 
The BDL model exhibits similarities and differences with the human cholestatic liver disease. Like humans, rodents develop bile duct and septal proliferations, inflammatory cell infiltration and liver fibrosis. However, the BDL model shows a more aggressive phenotype of the pathology, characterized by extensive areas of necrosis and formation of regenerative nodules, and death occurs within weeks or months (depending on the species) 12. Bile duct ligation is still the most used and better characterized model of cholestasis.

Growing availability of genetic mouse models, like the Mdr2 null mice, allows addressing specific questions on biliary phospholipid excretion. This model closely resembles the phenotype observed in a subtype of progressive familial intrahepatic cholestasis 13. Because of the large use of the BDL animal model, most (if not all) the studies cited in this review refer to it.

Several studies have already assessed mitochondria as relevant organelles in the pathophysiology of liver cholestasis 14-19. Mitochondria are key components of the cholestatic liver diseases, being involved in several steps of the progression of the pathology. Overall mitochondrial function is reduced during experimental cholestasis, and this is associated with an important metabolic disturbance, characterized by reduced fatty acid oxidation and ketone body formation, both during short- and long-term cholestasis 20, 21. Increased anaerobic glycolisis as a compensatory energy-producing mechanism in the cholestatic liver 17 is associated with depletion of glycogen stores 22 .

Profound metabolic alterations are also aggravated by inflammatory cell infiltration, release of proapototic factors and cell death. Mitochondria play a key role in the cholestatic liver because they link inflammation with apoptosis and energy production. Mitochondrial damage is not paralleled by proper mitochondrial biogenesis to promote restoration of mitochondrial function. Non-functional mitochondria are important sources of reactive oxygen species (ROS), which in turn can promote the onset of apoptosis and are also responsible for the activation of pro-fibrogenic mechanisms 23,24 . This is aggravated by a highly hydrophobic cellular milieu due to accumulation of potentially toxic bile acids, which further enhance mitochondrial dysfunction. The specific mechanisms involved in the onset and development of mitochondrial dysfunction in liver cholestasis are still controversial and will be the focus of this review.

\section{IMPAIRMENT OF MITOCHONDRIAL FUNCTION IN CHOLESTATIC LIVER DISEASE}

Direct and indirect evidences support a profound alteration of the energy homeostasis during cholestasis 17, $20,21,25$. Major alterations of energy metabolism in experimental cholestasis resemble metabolic alterations observed in patients with liver cirrhosis 26. Nevertheless, in the human pathology a systematic assessment of the energy metabolism and mitochondrial bioenergetics in patients with cholestasis alone is difficult to be obtained. Thus, experimental data from animal models are generally required to get a deep understanding of cholestatic liver disease.

After the onset of cholestasis, bile acids accumulate in the liver promoting cellular signaling but also exerting cytotoxic actions in hepatocytes 27. Hydrophobicity of these compounds seems to determine the degree of toxicity, being probably CDCA, DCA and litocholic (LCA) acids the most potent molecules in this regard 28. Part of the adverse effects of bile acids on mitochondrial bioenergetics could be related to the perturbation of mitochondrial membrane composition, as in fact CDCA and LCA can incorporate into mitochondrial membranes and reduce its content in phospholipids 19. Thus, this property of hydrophobic/lipophilic bile acids could alter membrane fluidity, Dym, ATP levels and ROS production, and increase the propensity to apoptosis.

Accumulation of bile acids negatively affects mitochondrial function and bioenergetics by directly impairing activities of the enzyme complexes of the ETC 19. Complex I and III activities in isolated mitochondria were negatively affected in presence of less than $100 \mathrm{mM}$ of DCA, CDCA or LCA, and complex IV was also inhibited by bile acids but higher concentrations were required 19. These concentrations are within the pathological range found in the liver during cholestasis in rodents 29 , and support a pathophysiological relevant role of these findings.

In the incubation of isolated rat mitochondria with succinate to assess complex II activity, addition of individual bile acids induced a decrease in ATP synthesis, ratio between ATP synthesis and oxygen consumption (P:O ratio), and respiratory control index (RCI) 30, 31. In another study, bile acids induced a loss of Dym under similar experimental conditions, and the effect was larger using CDCA, DCA and LCA than using less hydrophobic bile acids 30. These findings support our experimental observations in long-term bile duct ligated rats. In these studies a decrease in Dym was found in isolated hepatocytes by flow cytometry analysis 18 and confirmed in isolated mitochondria by polarographic determination 17.

ADP-stimulated mitochondrial respiration (state 3) is largely affected by bile acids and by cholestasis. In fact, addition of individual bile acids suppressed mitochondrial respiration in state 3 using succinate as substrate 30,31 . In an independent study, state 3 mitochondrial respiration was also decreased by incubating mitochondria with hydrophobic bile acids using Lglutamate, succinate, duroquinol or ascorbate/TMPD as substrates 19.

State 4 (non-ADP stimulated) mitochondrial respiration either does not change or increases in long-term cholestasis, as previously observed in mitochondria isolated from short-term cholestatic rats and dogs 17, 19, 30, 32, 33. The increase in state 4 
mitochondrial respiration found in some studies could be explained by an increased proton leak through the inner mitochondrial membrane, which pushes more electrons throughout the ETC without a parallel raise in ATP synthesis. The observed increase in state 4 respiration is already evident at 1 day after bile duct ligation, or even after few minutes after the addition of bile acids in vitro 30, 33. A short-term mechanism of ETC uncoupling induced by bile acids has been demonstrated, yet uncoupling protein 2 (UCP-2) already increases in the liver at transcript level at 4 and 8 days of extrahepatic cholestasis in rats 34 . Given a direct effect of bile acids on state 4 mitochondrial respiration, it is reasonable to suggest that these compounds could directly modulate UCP protein activity, but to date experimental evidence to support this hypothesis is lacking.

Several lines of evidence sustain an overall decrease in mitochondrial function during experimental cholestasis. An early study by Ozawa and colleagues showed that various respiratory parameters of liver mitochondria change in response to acute biliary obstruction in rabbits 35 . Despite a transient increase at $3 \mathrm{~h}$ from bile duct ligation, ATP production was already reduced at $6 \mathrm{~h}$, reached a minimum level at $24 \mathrm{~h}$, and maintained a plateau level for 7 days 35. More recent studies reported biochemical alterations of the mitochondrial function in response to acute and chronic cholestasis. Mitochondrial function decreased during short and long-term cholestasis ( 1 to 6 weeks) in rats 31 . In this study it was reported a progressive decrease in $\mathrm{RCI}$, oxygen consumption in ADP-stimulated respiration (state 3), and ATP synthesis using succinate or a-ketoglutarate as substrates 31 .

More recent research confirms some previous findings on mitochondrial respiration in cholestasis. ADP-stimulated oxygen consumption and RCI were markedly reduced using glutamate and malate as substrates, but not using succinate 17 . Thus, after long-term cholestasis there seems to exist a major impairment of complex I activity of the ETC rather than a general impairment of the respiratory function. Moreover, some compensatory adaptations of mitochondrial respiration could be responsible for maintaining coupling of mitochondrial respiration to ATP synthesis, at least under basal conditions. Despite a major overall impairment of the mitochondrial function during long-term cholestasis, the liver seems to cope to a certain extant with its metabolic requirements by adaptive hepatomegaly. Accordingly, at 5 weeks of cholestasis, oxygen consumption in perfused rat liver does not differ in BDL from sham-operated rats 36.

In the cholestatic liver some substances may exert an inhibitory effect on mitochondrial respiration, decreasing ETC activity and ATP synthesis. A progressive decrease in ATP synthesis in isolated liver mitochondria was observed throughout 3 weeks of cholestasis progression, but the decrease was less marked when ATP synthesis was determined in mitochondria isolated from hepatocytes 37. The authors proposed the existence of inhibitory compounds in the liver, which might impact on mitochondrial respiration even in competent organelles. In a different study it was found a $34 \%$ decrease in ATPase activity in the liver after 5 weeks of cholestasis, but this parameter did not change significantly in isolated liver mitochondria 36 . This discrepancy can be partly explained by the different source of mitochondria, which were from hepatocytes of cholestatic animals in the first study and from the whole liver (which includes all liver cells) in the second study.

Controversial results have also been presented about the activity of respiratory complexes. In one study, mitochondrial preparations from BDL rats presented significantly higher activity of complex III $(+35 \%)$, complex IV $(+40 \%)$ and citrate synthase $(+25 \%)$ than those from sham animals 38 . In contrast, in another study cytochrome c oxidase (complex IV) and ATPase (complex V) activity did not show any change in cholestatic versus control rats 39 . Finally, other data reported a decrease in the activity of complexes II, III, IV and V, but no change in citrate synthase activity after $90 \%$ ligation of the biliary tree 40 .

Mitochondrial function was also decreased in tissues other than the cholestatic liver lobes 40. Kanai and colleagues showed that $70 \%$ or $90 \%$ bile duct ligation produces a decrease in the mitochondrial oxygen consumption in state 3 at 4 weeks from the surgical procedure in the obstructed lobes 40 . Importantly, after $90 \%$ partial cholestasis significant changes were also observed in the non-obstructed liver lobe, which included a decrease in the RCI, in the P:O ratio, and in the activities of the five respiratory complexes 40 . Another study showed decreased mitochondrial respiration in state 3 and RCI in heart mitochondria at 1 week of BDL in rats 41 . These results suggest that compounds (e.g. bile salts) released in the circulatory system during cholestasis may produce mitochondrial dysfunction in extrahepatic tissues.

\section{MITOCHONDRIAL BIOGENESIS IN CHOLESTATIC LIVER DISEASE}

Mitochondrial function and mass have to be tightly regulated at the cellular level because of their vital role in energy production, metabolism, and signaling 42. The active process of biosynthesis of new mitochondria - called mitochondrial biogenesis - has to cope with the specific energy demand of the cell, so it requires a complex interaction between nuclear and mitochondrial genomes. The vast majority of the mitochondrial proteome (1100-1500 proteins, 43 is encoded by nuclear DNA (nDNA), but 13 essential proteins of the electron transport chain (ETC) are encoded by the mtDNA. 44. The whole process of mitochondrial biogenesis involves synthesis, import, and incorporation of proteins and lipids to the existing mitochondria, as well as replication of the mitochondrial DNA (mtDNA). Mitochondrial biogenesis is finely coordinated through the activity of several transcription factors at the nuclear level, being the most relevant nuclear respiratory factor 1 (NRF-1) and 2 (NRF-2/GABPa), estrogen related receptor a (ERR-a), the nuclear coactivators peroxisome proliferator activated receptor g coactivator 1a (PGC1a) and $\mathrm{b}$ (PGC-1b), and PGC-1 a -related coactivator (PRC) 44. These proteins promote the transcription of several 
mitochondrial genes in the nucleus, among which mitochondrial transcription factor A (TFAM), B1 (TFB1M), and B2 (TFB2M) are critical because they bind mtDNA and control mtDNA genes transcription and replication 45,46 .

During the progression of experimental cholestasis, it was observed an increase in mitochondrial protein content in the liver until day 14 after bile duct ligation, consistent with the observed increase in liver mass 47 . In turn, in comparison to pair-fed rats, mitochondrial mass per gram of liver did not change until day 14, but it decreased by $35 \%$ at day 2847 . After long-term partial cholestasis - that allows comparisons between obstructed and non-obstructed liver lobes - it was found a decrease in some subunits of the ETC in both the obstructed and the non-obstructed lobes 40. The authors proposed that an inhibition of the expression of nuclear and mitochondrial genes and/or an accelerated proteolysis might occur 40. Two studies confirmed the hypothesis of an impairment of mitochondrial and nuclear genes expression observed during short-term and long-term cholestasis 16,17 . However, no studies have so far supported the hypothesis that increased proteolysis may be the cause of mitochondrial dysfunction during the progression of cholestasis.

A decrease in mitochondrial biogenesis has been reported to appear very early in cholestasis. During the first 3 days of bile duct ligation, TFAM transcript and protein levels were lower in cholestatic animals than in control ones 16 . Nonetheless, in this study control rats were not pair-fed to BDL ones. Our group characterized most of the process that brings about a decrease in mitochondrial biogenesis during long-term cholestasis, and found that the problem arises both at nuclear and mitochondrial levels 17. NRF-2/GABPa levels were markedly decreased in the cholestatic rat liver and NRF-1 seemed to have reduced activity and was unable to maintain an active transcription of nuclear encoded-mitochondrial genes. This resulted in a decrease in TFAM, which is a target gene of NRF-1 and Nrf-2/GABPa, at mRNA and protein levels. Mitochondria themselves further contribute to the reduced biosynthetic potential, since synthesis of mitochondrial proteins in isolated liver mitochondria is largely decreased in the cholestatic rat starting from 2 weeks of bile duct ligation 47.

One major event associated to TFAM loss in the cholestatic liver was a marked (i.e. $\sim 65 \%$ ) decrease in mtDNA/nDNA ratio 17 . Three different situations can explain this finding: 1) a decrease in the copy number of mtDNA per mitochondrion, 2) a loss of mitochondria, which is in turn paralleled by a decrease in mtDNA amount per cell, 3) an increase in cell ploidy, which affects the mtDNA to nDNA ratio, independent of absolute abundance of mtDNA in the cell. To check for the third situation, we assessed cell ploidy in liver from cholestatic and sham operated-pair fed rats. Our results showed a non-significant increase in cell ploidy during cholestasis (unpublished results) that cannot account for the marked reduction ( $65 \%)$ in mtDNA observed after 4 weeks of bile duct ligation 17. According to previous studies, it was found that the decrease in mtDNA observed during cholestasis should be ascribed to a loss of mitochondria rather than to a decrease in mtDNA per mitochondria. Indeed, mtDNA content per mitochondria did not change throughout progression of cholestasis 40 . Taken together, these results suggest that mtDNA loss is secondary to an overall deregulation of mitochondrial biogenesis.

A special consideration should be made regarding mitochondrial protein import, a mechanism that promotes renewal of functioning organelles. Mitochondrial import is a process mediated by cytosolic chaperones, which allow contact between proteins containing mitochondrial target sequences and mitochondrial membrane proteins with receptor function 48. Upon recognition by the receptor, the imported protein is channeled through pore membrane proteins of the outer membrane, and subsequently of the inner mitochondrial membrane 48. After shuttling, the protein is cleaved by mitochondrial peptidases to give rise to a mature form, and then delivered to the correct mitochondrial location. To be imported into the mitochondrion, most proteins require ATP, GTP and an active proton-motive force 49, 50. The import pore includes protein translocases of the outer membrane (TOMs), which are required to take the initial interaction with cytosolic proteins. Among them, TOM20 shows higher affinity for targeting signals contained in the cleavable presequences, and TOM70 is usually required for proteins carrying internal targeting signals 48, 51, 52. During the progression of experimental cholestasis in rats, TOM20 levels increase in liver mitochondria but TOM70 levels are strongly reduced 17. Regardless possible compensatory mechanisms, loss of TOM70 in cholestatic liver could have an important impact on mitochondrial biogenesis and bioenergetics. Deletion of TOM70 in yeast demonstrated that this receptor has a role as docking site for cytosolic chaperones and also maintains solubility of proteins targeted to the mitochondrion 53. Indeed, a yeast mutant in TOM70 shows a reduced import of several mitochondrial proteins, including ATPase subunits and the chaperone Hsp60 53. In agreement with this report, Hsp60 decreases in liver mitochondria from cholestatic rats at 2 and 4 weeks after bile duct ligation, in association with the decrease in TOM70 17.

We also found that other mitochondrial proteins are differently regulated in the cholestatic liver. TFAM levels are largely decreased after 4 weeks of bile duct ligation, even to a greater extent than the decrease in the mRNA level 17. So far, it is unclear if there is a specific role for protein degradation in this regard. Eventually, TFAM depletion could be secondary to a decreased mitochondrial import, as evidenced by a decreased level of other mitochondrial proteins. Defects in mitochondrial protein import could indeed contribute to the development of the disease. Nonetheless, whatever the relevant mechanism in cholestasis, loss of mitochondrial proteins is not a general phenomenon. In fact, cytochrome c is a specific example of a mitochondrial protein that may even increase during cholestasis 17. To date, specific studies aimed at understanding the contribution of altered mitochondrial import machinery to the defective mitochondrial biogenesis and bioenergetics in the development of cholestatic liver disease are lacking.

\section{MITOCHONDRIAL-MEDIATED APOPTOSIS IN CHOLESTATIC LIVER DISEASE}




\subsection{General aspects}

Apoptosis is a ubiquitous form of programmed cell death occurring in human liver diseases 54-57. Hallmarks of apoptosis are cytoplasmic shrinkage, chromatin condensation, nuclear fragmentation, presence of plasma membrane blebbing, and fragmentation of the cell into apoptotic bodies 58. Upon completion of the process, ordered resorption of individual unwanted or dangerous cells minimizes leakage of intracellular components into the extracellular space and attenuates inflammatory responses. Apoptosis is generally initiated by external stimuli converging on death receptors (DRs) like tumor necrosis factor (TNF) receptor superfamily, member 6 (FAS/APO1/CD95) or TNF (ligand) superfamily, member 10 (TRAIL/APO2L), that oligomerize and lead to the formation of a death initiating signaling complex (DISC) consisting of Fas (TNFRSF6)-associated via death domain (FADD) and an initiator caspase, pro-caspase 8/10 59. In type I cells, processed caspase- 8 is able to directly activate other effector caspases (i.e. CASP-3, 6 and 7), which in turn trigger the execution of apoptosis of the cell. Conversely, in type II cells caspase- 8 mediates the activation of the BH3 interacting domain death agonist (BID) leading to the activation of BCL2-associated $\mathrm{X}$ protein (BAX) and/or BCL2-antagonist/killer 1 (BAK) to the mitochondrion, the release of pro-apoptotic factors from mitochondria, formation of the apoptososme, and then activation of caspase-9 and effector caspases 60,61 . In the latter case, a mitochondrial amplification loop becomes essential to the execution of apoptosis.

Hepatocytes have for long time been considered type II cells because experimental evidences supported the notion that CASP-3 is activated through the mitochondrial pathway in these cells 62 . Nonetheless, more recent research defines that hepatocytes behave as type I (mitochondrial-independent apoptosis) or type II cells (mitochondrial-dependent apoptosis) depending on the intensity of the apoptotic stimulus 63, 64. In one study it has been shown that loss of X-chromosome linked inhibitor of apoptosis (XIAP) or an increase in second mitochondria-derived activator of caspases (SMAC/DIABLO) in mice rendered hepatocytes susceptible to apoptosis independent of BID upon Fas stimulation, like type I cells 63. In another study it has been proposed that BID is an amplifier of a weak DR signal, and upon increased Fas stimulation, quiescent and non-quiescent hepatocytes are more sensitive to Fas ligand-induced (FasL-induced) apoptosis. Furthermore, hepatocytes' cross-talk with the extracellular matrix can switch the mode of apoptosis from type II to type I. Hepatocytes cultured on collagen, which more closely resemble physiological conditions, undergo mitochondrial-independent apoptosis upon FasL stimulation 65. Thus, despite a recognized paramount role for mitochondria in the induction of apoptosis in hepatocytes, they can undergo apoptosis also in a mitochondrial-independent fashion depending on the intensity of the stimulus and on the interaction with the extracellular environment.

\subsection{Apoptosis in liver cholestasis: time course and mechanisms}

Liver injury during cholestasis is characterized by hepatocyte and cholangiocyte apoptosis. Caspase- 3 immunostaining and activity have been previously used to assess the evolution of apoptosis in the cholestatic rat liver. These results showed that apoptosis is significantly elevated during the first week after bile duct ligation, declining thereafter 66,67 . Though probably less abundant, apoptosis is still present in the cholestatic liver during mid- and long-term evolution of the disease 17,18 . Indeed, flow cytometric evaluation of apoptosis in isolated hepatocytes from cholestatic rat liver revealed that apoptosis is still significant at 4 weeks from bile duct ligation 18.

During progression of cholestasis, multiple mechanisms of apoptosis are likely to act synchronously to promote cell death in the liver parenchyma. At three days from the onset of cholestasis, apoptosis in the liver seems to be predominantly Fasdependent as assessed by a reduced level of apoptosis in Fas-deficient lpr (lymphoproliferation) mice 68. Nonetheless, at day 7 from the bile duct ligation, apoptosis was attenuated to a lesser extent in Fas-deficient mice, indicating that other mechanisms were promoting apoptosis after bile duct ligation 68. Consistent with molecular alterations of mitochondrial physiology, mitochondrial-dependent mechanisms are largely contributing to cell death after bile duct ligation. An alteration of the ratio between BAX and B-cell CLL/lymphoma 2 (BCL-2), which peaks at 3 days after bile duct ligation, has been described during cholestasis in rats 69. Despite the majority of apoptosis fades away at the end of the first week from bile duct ligation, residual liver apoptosis is still detectable after 2 weeks, with increased BAX/BCL-2 ratio and cleaved caspase-3 in rat liver 17.

Further evidence supports a central role of the mitochondrion as a contributor to the apoptotic response in the cholestatic liver. Loss of mitochondrial membrane potential (Dym) during long-term cholestasis has been clearly demonstrated by two independent techniques, namely flow cytometry and polarography 17, 18. Under proapoptotic stimuli, opening of mitochondrial permeability transition (MPT) pores develops and causes collapse of the Dym with release of propoaptotic factors that bring about apoptosome formation and caspase activation. In isolated mitochondria from rat liver, chenodeoxycholic acid (CDCA) has been found to be a direct inducer of MPT, accompanied by membrane depolarization, release of matrix calcium, and osmotic swelling 70. Other hydrophobic bile acids are similarly able to cause mitochondrial depolarization and MPT in isolated mitochondria 30,71-73, thus creating a direct link between bile acids and mitochondrial-mediated apoptosis. In this regard, mitochondria are likely to play a key role in apoptosis progression and during long-term cholestasis. A direct causal effect of hydrophobic bile acids on Dym has also been demonstrated in different studies using isolated hepatocytes 74,75 or HepG2 hepatocytes 76. After bile duct ligation, Bid promotes apoptosis in wild type and Fas-deficient mice, and Bid antisense administration to wild type mice promotes a reduction of apoptosis and serum AST levels 75 . Similarly, Bid antisense reduces apoptosis in GCDC treated hepatocytes 75. Despite clear evidence of the involvement of the mitochondrial pathway during 
cholestasis-induced apoptosis, the role of Bid can be controversial (see section 4.4), and more studies are needed to clarify the role of this pro-apoptotic protein in chronic cholestasis.

\subsection{Bile acids promote apoptosis in liver}

Primary bile acids are synthesized exclusively in the liver using cholesterol as precursor. In the intestine, bacterial flora further processes these compounds to form secondary bile acids, which also have relevant roles in mitochondrial-dependent cell death. Given that bile acids accumulate in the liver and in plasma during cholestasis, they are likely to play an important role in the progression of the pathology 77-79. High concentration of potentially toxic bile acids in the liver can elicit diverse necrotic and apoptotic mechanisms, likely independent of the detergent action of bile acids 27. Exposure of primary hepatocytes and hepatocyte cell lines to bile acids promotes cell death by either apoptosis or necrosis, depending on the concentration of these compounds $74,75,77$. The mechanisms whereby bile acids damage hepatocytes are not fully understood. However, they are able to promote apoptosis by stimulation of both extrinsic (i.e. DR-mediated) pathways 68,80 and intrinsic (i.e. mitochondriallymediated) mechanisms of apoptosis 75 .

Bile acids are direct inducers of apoptosis in hepatocytes through ligand-dependent and ligand-independent activation of Fas 77. GCDC treatment increases oligomerization of Fas, recruitment of FADD, mitochondrial permeabilization and activation of effector proteases, in the absence of detectable FasL mRNA 77. In McNtcp.24 cells, which resemble hepatocyte behavior, GCDC promotes intracellular trafficking of Fas by a Golgi- and microtubule-dependent pathway, to finally increase Fas density on the plasma membrane 81 .

The hydrophobic bile acid glycochenodeoxycholate (GCGC) has been proposed to be a key player in the induction of hepatocyte apoptosis, because exposure of hepatocytes to GCDC results in the induction of cell surface receptor TRAIL-R2/DR5 at transcriptional level, and also inactivation of FADD-like apoptosis regulator (cFLIP/cFLAR) by phosphorylation $75,82,83$. Thus, GCDC dually sensitizes hepatocytes to cell-induced apoptosis. Bile acids are important mediators of the apoptotic response, as TRAIL alone does not induce cell death in normal hepatocytes 75. During experimental cholestasis induced by bile duct ligation, hepatocytes overexpress TRAIL-R2 and are sensitized to exogenous administration of TRAIL 84. Accordingly, both hepatocyte apoptosis and liver injury are significantly reduced in TRAIL null mice during cholestasis 80 .

Thus, death receptors such as Fas and TRAIL-R2 are involved in liver injury induced by cholestasis. Livers from mice deficient in Fas exhibited less cell death by necrosis and apoptosis as well as reduced fibrosis after bile duct ligation $68,85$. Collectively, these data suggest that GCDC-induced hepatocyte apoptosis involves ligand-independent oligomerization of Fas, as it occurs without significant elevations of FasL levels 81.

\subsection{Anti-apoptotic response to cholestatic injury}

Cell injury triggers not only apoptosis but also a pro-survival response, which is dependent on different mechanisms of regulation, either at transcriptional or post-transcriptional level. After bile duct ligation, activation of nuclear factor-kappa B (NF$\mathrm{kB}$ ) in hepatocytes promotes expression of anti-apoptotic proteins and survival 66, whereas overexpression of IkB (a NF-kB repressor) in the liver increases apoptosis and liver damage 67. NF-kB-mediated survival was dependent on the regulation of anti-apoptotic genes A1/Bfl and cIAP2 at the transcriptional level. Apparently, bile acids are direct mediators of this pro-survival response 66, 86. An increase in the level of the anti-apoptotic BCL-2 has also been observed in liver mitochondria during the progression of the pathology 17, 69, possibly to withstand the increase in Bax incorporation in the mitochondrial membrane.

At an early stage of cholestasis some kind of resistance to cell death may develop. During this early stage, increased cardiolipin content in the mitochondrion alters the composition of the mitochondrial membrane and decreases the probability of MPT pore formation, and the threshold of apoptosis increases 87. Another adaptive response against cell death that accounts for apoptosis resistance is the phosphorylation of Bid, which impairs truncation (tBid) and activation of the protein and hence the promotion of apoptosis 88. Paradoxically, mitochondrial dysfunction observed during cholestasis might act as a defense mechanism against bile acids toxicity. In HCT-116 colon carcinoma cells, inhibitors of complex I, III and V largely decrease deoxycholic acid (DCA)-induced cell apoptosis 89. Thus, several mechanisms of mitochondrial and extra-mitochondrial origin cooperate to confer resistance against apoptosis in the liver, but risking to maintain damaged (potentially dysfunctional or even malignant) cells alive.

Despite apoptosis is largely considered a process to restore liver function homeostasis, there is a strong mechanistic link between hepatocyte apoptosis, inflammation, and fibrosis in chronic liver diseases. Engulfment of apoptotic bodies by phagocytic cells leads to their activation and in turn to secretion of chemokines as well as recruitment of leukocytes and inflammatory cells into the liver 90-92. Apoptosis contributes to hepatic fibrogenesis through activation of hepatic stellate cells (HSC) by direct and indirect mechanisms related to the destiny of apoptotic bodies. Phagocytosis of apoptotic bodies by Kupffer cells results in the release of transforming growth factor b (TGF-b), which activates HSC 93. If HSC are responsible for phagocytosis of the apoptotic bodies then the up-regulation of TGF-b in the same HSC leads directly to their activation through an autocrine mechanism 94. Indeed, engulfment of apoptotic bodies by HSC is a stimulus for HSC activation and cause secretion of increasing amounts of collagen, leading to liver fibrosis 91. 


\section{MITOCHONDRIAL OXIDATIVE STRESS IN CHOLESTATIC LIVER DISEASE}

Oxidative stress is a common feature of obstructive cholestasis 95 , primary biliary cirrhosis 96,97 , and sepsis-induced cholestasis 98, and it has been linked to the progression of cholestatic liver injury. During cholestasis, oxidative stress is a systemic phenomenon since lipid peroxidation increases in plasma, kidney, brain and heart from rats at $24 \mathrm{~h}$ after bile duct ligation 99. Oxidative stress is the imbalance between pro-oxidant agents and antioxidant agents in favor of the formers 100. Increases in oxidized glutathione (GSSG) - an index of glutathione oxidation -, 8-hydroxy-2'-deoxyguanosine - an index of DNA oxidation -, and lipid oxidation occur in rat liver at 15 days of bile duct ligation or thereafter 101-103.

Hepatic GSH is depleted in long term cholestasis 18, 102 due to lower GSH synthesis and down-regulation of GSH synthetic enzymes 18, 104. During cholestasis, tumor necrosis factor alpha (TNF-a) and toxic bile acids have been involved in liver injury and hepatocyte apoptosis 68, 80. It is known that mitochondrial glutathione depletion sensitizes hepatocytes to apoptosis induced by TNF-a 105. In the long term cholestasis there is depletion of reduced glutathione (GSH) in liver mitochondria 18 and consequently hepatocytes should be prone to cell death under this condition. Oxidative stress is especially marked in liver mitochondria in the long term experimental cholestasis, i.e. at 14 days after bile duct ligation or thereafter, as evidenced by a remarkable increase in lipid peroxidation and GSSG together with depletion of GSH 18, 101, 106. Furthermore, high-fat diets increased lipid oxidation in liver mitochondria and hepatic injury after bile duct ligation 107.

Nrf2, nuclear factor erythroid derived 2 like $2(\mathrm{Nrf} 2)$ is one of the transcription factors regulating inducible and constitutive gene expression mediated by the antioxidant response elements (ARE), which are found in the promoter regions of two major detoxication enzymes, namely glutathione S-transferase A2 (GSTA2) and NADPH:quinone oxidoreductase (NQO1) 108. It is noteworthy that toxic bile acids induce a switch from Nrf2 to c-avian musculoaponeurotic fibrosarcoma/V-maf musculoaponeurotic fibrosarcoma oncogene homolog G (c-Maf/MafG) ARE nuclear binding, leading to decreased expression of GSH synthetic enzymes and contributing to liver injury during chronic cholestasis 104 . Ursodeoxycholic acid (UDCA) and Sadenosyl methionine treatment prevented this decrease preserving GSH levels and preventing liver injury 18,104 . The beneficial effects of UDCA are mediated by activation of the PI3K/Akt/Nrf2 pathway 97, 109, 110. In agreement with an important contribution of oxidative damage to the progression of the cholestatic diseases, pretreatment with vitamin $\mathrm{E}$ significantly diminished mitochondrial lipid peroxidation and hepatocyte damage in rats receiving intravenous taurochenodeoxycholic acid (TCDCA) 111. The antioxidants idebenone - a coenzyme Q analogue - or a-tocopherol inhibited the generation of reactive oxygen species (ROS) in isolated rat liver mitochondria and in isolated hepatocytes as well as the mitochondrial membrane permeability transition and subsequent apoptosis induced by GCDCA in rat hepatocytes 74, 112. Summarizing, these data support the relevancy of ROS in liver cholestasis.

Mitochondria are likely major producers of ROS during cholestasis. In agreement, adenoviral therapy to overexpress MnSOD was more effective than $\mathrm{Cu} / \mathrm{ZnSOD}$ to reduce liver damage, fibrosis and 4-hydroxynonenal (a marker of lipid peroxidation) 113. Nevertheless, these findings cannot exclude a significant role of other sources of ROS in cholestatic injury apart from liver mitochondria. Accordingly, inhibition of the ROS generating enzyme xanthine oxidase by oxypurinol reduced hepatocellular injury after bile duct ligation in rats without affecting mitochondrial lipid peroxidation 114. These authors suggested that a component of cholestatic injury might be caused by oxidative stress from a source outside of the hepatocyte. In this regard, the increase in plasma homocysteine that occurs after bile duct ligation may contribute to oxidative stress and tissue damage 115 .

In contrast to these results, Baron and Muriel reported that treatment with the antioxidants vitamin $\mathrm{E}$ or trolox prevented the increase in lipid peroxidation and GSSG levels in the liver without affecting tissue injury assessed by serum enzyme activities and histology after 7 days of bile duct ligation in rats 116 . This apparent controversy might be explained by the adaptive response that occurs in the liver in the short term of cholestasis, evidenced by the increase in hepatic GSH levels at 1 and 5 days after bile duct ligation 102, which may uncouple oxidative stress and tissue damage at this stage. In addition, the experiments mentioned previously on the beneficial effects of vitamin E were performed in hepatocytes in vitro or in perfused liver, whereas the experiments by Purucker and colleagues were performed in vivo.

Mitochondrial ROS trigger signal transduction pathways under physiological conditions, but in excess they promote oxidative stress and oxidative damage. Bile acids such as DCA and taurodeoxycholic acid (TDCA) increased mitochondrial ROS production in hepatocytes 117. Mitochondrial ROS may also cause inactivation of protein tyrosin phosphatases (PTPase) that triggers tyrosin phosphorylation of the epidermal growth factor receptor ERBB1 and subsequently activation of mitogenactivated protein kinase kinase $1 / 2$ and mitogen-activated protein kinase $1 / 2$ (MEK1/2-ERK1/2) 117. Activation of the ERK1/2 and AKT pathways by bile acids protects against hepatocyte apoptosis through reduction of the FAS-R-caspase $8 / 9 / 3$ pathway 118,119 . Activation of these pathways was abolished in Rho 0 cells or by cyclosporine A and bongkrekic acid, which inhibit mitochondrial permeability transition and electron transport 117.

However, this protection is ineffective during chronic cholestasis due to generation of large amount of mitochondrial ROS. In turn, ROS could contribute to maintain apoptosis active, as observed during long-term cholestasis 17,18 . Bile acid toxicity in hepatocytes seems to be dependent on the generation of mitochondrial ROS and accordingly, UDCA reduced DCA- 
induced hepatocyte killing at least in part by inhibiting DCA-induced mitochondrial permeability transition and ROS generation 72, 73. Chronic oxidative stress may also contribute to apoptosis by inducing a severe depletion of mitochondrial cardiolipin content found in the long term cholestasis 18. Cardiolipin normally protects against apoptosis by providing an increased pool of negative ions that bind $\mathrm{Ca} 2+$, thereby preventing it from binding to protein sites that induce opening of mitochondrial permeability transition pores 120 .

Dent and coworkers 117 proposed that during reabsorption of bile acids with nutrients after feeding, bile acid-induced mitochondrial ROS modulate AKT/glycogen synthase activity as well as ERK1/2/LDL receptor helping in the regulation of glucose and lipid metabolism. However, during chronic cholestasis prolonged exposure to high concentrations of bile acids causes oxidative stress, uncoupling growth factor receptors from protective downstream signaling pathways 117 . Thus, marked glutathione depletion and oxidation as well as lipid peroxidation occur in liver mitochondria upon chronic cholestasis 18,106 without activation of the AKT pathway 17. It is worth noting that the mitochondrial concentration of GSH exhibited a positive correlation with the activity of some respiratory chain complexes, particularly with succinate:ferricytochrome c oxidoreductase, whereas the mitochondrial concentration of thiobarbituric acid reacting substances (TBARS) - as an index of lipid peroxidation showed a negative correlation. Serum ALT and alkaline phosphatase activities as well as bilirubin levels correlated significantly with mitochondrial levels of conjugated dienes and TBARS 107. Furthermore, the beneficial effects of UDCA in the treatment of chronic cholestasis are associated with a partial prevention of both glutathione depletion and oxidation in liver mitochondria as well as with a decrease in mitochondrial ROS generation 18.

In addition, oxidative stress contributes to the onset and progression of liver fibrosis induced by chronic cholestasis 24 . ROS and lipid peroxidation products, such as 4-hydroxynonenal, promote fibrogenesis through redox signalling that leads to upregulation of the transforming growth factor beta, activation of HSC, and modulation of the expression of metalloproteinases and their specific inhibitors 24, 121.

Oxidative stress and particularly the increased mitochondrial ROS production that occurs in biliary cirrhosis 18 should induce mitochondrial biogenesis through activation of NRF-1 and PGC-1a 122. Indeed, oxidative stress normally induces NRF-1 phosphorylation and up-regulation of TFAM expression via phosphatidylinositol 3-kinase (PI3K) and AKT/protein kinase B 123. However, AKT was not phosphorylated and PGC-1a and TFAM were down-regulated in biliary cirrhosis avoiding the stimulation of mitochondrial biogenesis through this pathway 17.

In addition to be a consequence of cholestasis, oxidative stress can also promote cholestasis on its own 124. Oxidative stress impairs the hepatocyte capability to secrete and retain bile salts in the bile canaliculus and induces actin-cytoskeletal disarrangement causally linked to internalization of canalicular transporters and disarrangement of tight-junctional structures 124 . Indeed, oxidative stress triggers reversible retrieval of the multidrug resistance-associated protein 2 (Mrp2), a biliary transporter involved in bile salt-independent bile flow, from the canalicular membrane of hepatocytes and its translocation into cytosolic putative vesicles via the redox-sensitive balance of protein kinase A/C (PKA/PKC) activation 125.

\section{DUAL ROLE OF INFLAMMATION IN CHRONIC CHOLESTASIS}

In cholestasis the accumulation of bile acids - especially hydrophobic ones - causes hepatocyte injury that results in the activation of Kupffer cells and infiltration of other inflammatory cells into the liver, particularly neutrophils 126 . This second phase of generalized injury triggered by the innate immune system aggravates liver injury promoting fibrosis and eventually chronic liver failure 80,85 . Consequently, long term cholestasis is a chronic inflammatory condition characterized by liver fibrosis together with maintained expression of pro-inflammatory cytokines and inducible nitric oxide synthase (iNOS) 17, 126, 127.

Inflammation seems to play a dual role in the development of liver damage during cholestasis. On the one hand, neutrophils and tumor necrosis factor-related apoptosis-inducing ligand (TRAIL) significantly promote liver injury after bile duct ligation, whereas on the other hand Kupffer cells protect against cholestatic liver injury 128. TRAIL is a death ligand released by cells of the innate immune system - especially natural killer cells, natural killer T cells, and monocytes - which plays a key role in liver injury during cholestasis 80 . Accordingly, apoptosis was markedly reduced in TRAIL knockout mice subjected to bile duct ligation, and it was associated with reduced liver fibrosis and serum ALT values 80 .

Kupffer cells play distinct roles in the cholestatic liver disease. Phagocytosis of apoptotic bodies by Kupffer cells results in the release of TGF-b, which activates HSC 93. Nevertheless, Kupffer cell-depleted mice and interleukin-6-deficient mice exhibited more liver injury, particularly necrosis, than wild type animals after bile duct ligation 128. It was suggested that Kupffer cells produce cytokines, chemokines and toxic products that would contribute to hepatocyte death, inflammatory infiltrate and activation of HSC 129, 130. However, Kupffer cells reduce cholestatic liver injury by cytokine-dependent mechanisms that mainly involve secretion of interleukin 6128 . Indeed, exogenous IL-6 completely reversed the consequences of

Kupffer cell depletion 128. It seems that Kupffer cells protect against the increase in bacterial endotoxin derived from the gut that occurs during cholestasis due to impairment in the integrity of the intestinal mucosa 131. 
Pro-inflammatory cytokines, particularly TNF-a and interleukin-2, are potent inducers of intrahepatic cholestasis 132 . Indeed, TNF-a inhibits bile flow and hepatocellular bile salt uptake in the rat 133, 134. This inflammation-induced cholestasis results mainly from inhibition of expression and function of hepatocellular transport systems for bile salts 132. Consequently, chronic inflammation associated with chronic cholestasis may generate a deleterious positive feed-back mechanism that potentiates each other.

However, the role of TNF-a in chronic cholestasis is dual and paradoxically this pro-inflammatory cytokine seems to be more beneficial than detrimental. TNF-a may promote hepatocyte apoptosis via TNFRSF1A-associated via death domain (TRADD), receptor (TNFRSF)-interacting serine-threonine kinase 1 (RIP), and mitogen-activated protein kinase 8 and 9 (JNK1 and JNK2) 135 and thus aggravate cholestasis 132, but paradoxically TNF-receptor-deficient mice subjected to chronic cholestasis showed enhanced hepatocellular necrosis 127 . TNF-a protects by inducing the expression of multidrug resistanceassociated protein 3 expression on the basolateral membrane of hepatocyes, favoring the efflux of bile salts and glucuronide conjugates 127. In addition, TNF-a may also trigger activation of an anti-apoptotic pathway mediated by NF-kB transcription of survival genes, such as growth arrest and DNA-damage-inducible protein beta (GADD45beta), manganese superoxide dismutase (MnSOD), and CASP8 and cFLIP/cFLAR 135.

\section{CHOLESTATIC LIVER DISEASE AS A SECONDARY MITOCHONDRIOPATHY}

Disorders that affect mitochondrial oxidative phosphorylation usually have an important impact on cellular metabolism, leading to liver diseases and often to multisystem alterations, and they have been called mitochondrial hepathopaties 136 . They have been divided into primary disorders 137,138 , in which the mitochondrial defect is the primary cause of the liver disease, and secondary disorders that are caused either by genetic defects originally of non-mitochondrial proteins or by acquired injury to mitochondria 139. Most primary mitochondrial hepatopathies are caused by mutations in nuclear genes, such as mitochondrial polymerase $\mathrm{g}$ (POLG), rather than by deletions or rearrangements of mitochondrial DNA 136. They include electron transport defects, fatty acid oxidation and transport defects, disorders of the mitochondrial translational process, urea cycle enzyme deficiencies and phosphoenolpyruvate carboxykinase deficiency 136. Among them, the mitochondrial DNA depletion syndrome should be highlighted because it is characterized by a dramatic reduction in the mtDNA copy number in different tissues $(<10 \%$ of the normal amount of mitochondrial DNA vs nuclear DNA), insufficient synthesis of mitochondrial complexes I, II, IV, and V, together with lactic acidosis, cholestasis, steatosis, and fibrosis 136.

It is well known that severe mitochondrial dysfunction occurs in chronic cholestasis in rodents and in humans. Indeed, this liver disorder leads to a marked loss of Dym as well as to decreased ATP production, fatty acid oxidation, and ketone body formation 18-21, 140-142. In addition, cholestasis and progressive liver fibrosis have been associated with mtDNA depletion in infants 143. Recently, we have reported that long-term cholestasis is also characterized by a remarkable reduction in the mitochondrial DNA to nuclear DNA ratio, i.e. $35 \%$ of the normal ratio 17 , probably due to a reduced TFAM protein import. TFAM, which regulates mtDNA transcription and replication, also functions as histone-like protein that protects mtDNA. Hence, a marked reduction in TFAM levels would lead to mtDNA instability. Accordingly, we have shown that long-term cholestasis leads to mtDNA deletions 17. Chronic mitochondrial oxidative stress might be responsible, at least in part, for the increased frequency of mtDNA deletions 144. It is noteworthy that somatic mtDNA mutations are associated with hepatocarcinogenesis 123.

Therefore and taken into account these mtDNA mutations together with the severe mtDNA depletion and mitochondrial impairment, we have proposed that long-term cholestasis should be considered a secondary mitochondrial hepatopathy 17. Other secondary mitochondrial hepatopathies are Reye's Syndrome, Wilson's Disease, valproic acid hepatotoxicity, and liver diseases induced by nucleoside reverse transcriptase inhibitors 136. It is worth noting that identical mutations in mitochondrial DNA may give rise to great variations in phenotype and severity due to heteroplasmia 136. Indeed, cells may harbor both normal and mutant mitochondrial DNA in various amounts due to random partitioning during cell division.

\section{MITOCHONDRIA AS PUTATIVE TARGETS FOR THERAPEUTIC INTERVENTION IN CHOLESTASIS}

The knowledge and understanding of cholestatic liver diseases is growing, especially at the experimental level. Nonetheless, pharmacological treatments have not evolved so much since the introduction of UDCA as a therapeutic agent. UDCA is one of the major compounds found in the bear bile and it is currently used for curing hepatic and biliary disorders. Bear bile has been used in traditional Chinese medicine for thousands of years, because it was found to have a wide range of pharmacological actions with little toxicological side effects. Professor Olof Hammarsten from the University of Uppsala (Sweden) was the first to isolate an unknown bile acid from the bile of the Polar bear and named it "ursocholeinsäure", later renamed ursodeoxycholic acid by Prof. Shoda 145. Since mid 1950's, Japanese scientists succeeded in chemically synthesizing UDCA from cholic acid 146, which is currently made synthetically in large quantities and widely used in Western medicine. Nowadays, UDCA is the only drug approved by the Food and Drugs Administration (FDA) for the treatment of primary biliary cirrhosis (PBC) patients without liver transplantation. The efficacy of UDCA for treatment of recurrent PBC after liver transplantation remains less well known. 
Putative mechanisms of action of UDCA (or its taurine-conjugated form TUDCA) include: anti-apoptotic 147, 148, regulation of immune function 149, 150, anti-inflammatory 151, promotion of choleresis 152-154, coordination and maintenance of mitochondrial integrity 18 and alteration of cell signaling 155, 156. Despite several relevant studies in vivo with animals and in vitro with cells and isolated organelles (e.g mitochondria), still poor is the knowledge of the mechanisms of action of this molecule in the human being. UDCA has been proposed to protect hepatocytes by decreasing mitochondrial peroxide production in BDL rats 18, a mechanism that probably contributes to the anti-apoptotic action of UDCA. UDCA could have a have a beneficial role by increasing antioxidant defenses in liver cells 157 . This mechanism of protection is supported by experimental evidence with PBC patients 97. Kawata K. and collaborators studied a group of 13 PBC patients before and after UDCA treatment. Compared with pre-treatment, UDCA was able to increase total and phosphorylated levels of Nrf-2. This was associated with an increase in the levels of thioredoxin (Trx) and thioredoxin reductase 1 (Trxr1), the only enzyme in charge of reducing Trx using NAPDH as a cofactor 97. These findings support previous experimental knowledge of an antioxidant effect of UDCA 18,157 . Thus, by this mechanism UDCA is suggested to protect mitochondria from oxygen radical-induced dysfunction. Other mechanisms through which UDCA ameliorates liver function in humans are yet to be established.

Given the clear implication of mitochondrial dysfunction in the progression of cholestatic liver diseases, novel therapeutic approaches could be considered. Selective delivery of mitochondrial antioxidants such as MitoQ - or related compounds 158-160 -, could be considered alone or in combination with UDCA. MitoQ, which consists of a quinone/quinol moiety linked to a triphenylphosphonium (TPP) moiety through an alkyl chain 159, easily passes through the phospholipid bilayer and accumulates in the mitochondrial matrix driven by the Dym 161. MitoQ is an effective antioxidant against lipid peroxidation 162, 163 and peroxinitrite formation 164, but minor is its reactivity towards hydrogen peroxide 164. This compound has been shown to have other biological activities, such as preventing the loss of Dym and decreasing caspase activity in response to apoptotic stimuli 162. Conversely to MitoQ, uptake of other mitochondrial antioxidants like SS peptides (tetrapeptides with alternating aromatic residues and basic amino acids) was shown to be almost independent of Dym. These compounds also have important scavenging effects and can be used to reduce apoptosis 160 .

Long-term oral administration of MitoQ to mice, rats and humans has been proven to be safe 165-167. After oral administration, it accumulates in heart, liver, kidney, skeletal muscle, brain and fat 165 . Experimentally, this mitochondrial antioxidant has been successfully used to protect against cardiac ischemia reperfusion (I/R) injury in rats 168 and mice 169 , increased blood pressure in spontaneously hypertensive rats 170 , and organ damage in a lipopolysaccaride-peptoglycan model of sepsis 171. In humans, MitoQ has been used to treat chronic hepatitis C virus (HCV), a disease with evidence for increased oxidative stress and mitochondrial damage 172. In this study MitoQ was proven effective to reduce hepatic damage (assessed as serum ALT), without alteration of the viral load. Because of the safety of this mitochondrial antioxidant, MitoQ could be a

possible therapeutic approach to test for the treatment of cholestatic liver diseases, which have been shown to be associated with high levels of mitochondrial oxidative damage.

In conclusion, mitochondrial dysfunction may cause oxidative stress, apoptosis and fibrosis. Mitochondrial dysfunction is also central to a severe metabolic alteration in the cholestatic liver, a condition worsened by a defective induction of mitochondrial biogenesis at nuclear and mitochondrial level. Therapeutic approaches to treat the cholestatic liver and associated diseases (like PBC) rely on the partial and not well understood efficacy of UDCA, the only approved treatment at present. A more targeted antioxidant therapy to rescue mitochondrial function, such as MitoQ or other mitochondrial antioxidants, might have beneficial effects that complement UDCA treatment.

\section{CONCLUDING REMARKS}

In this review we have focused on the contribution of mitochondria to the pathogenesis of liver disease in long-term cholestasis, elucidating the major mechanisms known so far to explain the mitochondrial impairment in this chronic disease. In particular, the contribution of inflammation and apoptosis as well as the lack of stimulation of mitochondrial biogenesis, the marked mitochondrial DNA depletion and occurrence of mitochondrial DNA mutations to the progression of this severe disease have been highlighted. All these findings certainly support the consideration of long term cholestasis as a secondary mitochondrial hepatopathy.

\section{REFERENCES}

1. M. Trauner, P. J. Meier and J. L. Boyer: Molecular pathogenesis of cholestasis, N Engl J Med 339, 1217-1227 (1998)

2. E. A. Shaffer, Cholestasis: the ABCs of cellular mechanisms for impaired bile secretion--transporters and genes, Can J Gastroenterol 16, 380-389 (2002)

3. R. O. Elferink, Cholestasis, Gut 52 Suppl 2, ii42-8 (2003) 
4. M. Wagner, G. Zollner and M. Trauner: New molecular insights into the mechanisms of cholestasis, J Hepatol 51, 565-580 (2009)

5. G. Alpini, S. S. Glaser, Y. Ueno, R. Rodgers, J. L. Phinizy, H. Francis, L. Baiocchi, L. A. Holcomb, A. Caligiuri and G. D. LeSage: Bile acid feeding induces cholangiocyte proliferation and secretion: evidence for bile acid-regulated ductal secretion, Gastroenterology 116, 179-186 (1999)

6. M. K. Li and J. M. Crawford: The pathology of cholestasis, Semin Liver Dis 24, 21-42 (2004)

7. E. J. Heathcote, Diagnosis and management of cholestatic liver disease, Clin Gastroenterol Hepatol 5, 776-782 (2007)

8. S. O. BYERS and M. FRIEDMAN: Plasma cholesterol in rats following ligation of the bile duct and intravenous injection of free cholesterol, Am J Med 8, 535-536 (1950)

9. J. M. Johnstone and E. G. Lee: A quantitative assessment of the structural changes the rat's liver following obstruction of the common bile duct, Br J Exp Pathol 57, 85-94 (1976)

10. Y. Osawa, E. Seki, M. Adachi, K. Taura, Y. Kodama, S. V. Siegmund, R. F. Schwabe and D. A. Brenner: Systemic mediators induce fibrogenic effects in normal liver after partial bile duct ligation, Liver Int 26, 1138-1147 (2006)

11. S. Heinrich, P. Georgiev, A. Weber, A. Vergopoulos, R. Graf and P. A. Clavien: Partial bile duct ligation in mice: a novel model of acute cholestasis, Surgery 149, 445-451 (2011)

12. P. Georgiev, W. Jochum, S. Heinrich, J. H. Jang, A. Nocito, F. Dahm and P. A. Clavien: Characterization of time-related changes after experimental bile duct ligation, Br J Surg 95, 646-656 (2008)

13. J. M. de Vree, E. Jacquemin, E. Sturm, D. Cresteil, P. J. Bosma, J. Aten, J. F. Deleuze, M. Desrochers, M. Burdelski, O. Bernard, R. P. Oude Elferink and M. Hadchouel: Mutations in the MDR3 gene cause progressive familial intrahepatic cholestasis, Proc Natl Acad Sci U S A 95, 282-287 (1998)

14. I. Grattagliano, S. Russmann, C. V. Diogo, L. Bonfrate, P. J. Oliveira, D. Q. Wang and P. Portincasa: Mitochondria in Chronic Liver Disease, Curr Drug Targets (2011)

15. S. Krahenbuhl, Alterations in mitochondrial function and morphology in chronic liver disease: pathogenesis and potential for therapeutic intervention, Pharmacol Ther 60, 1-38 (1993)

16. M. M. Tiao, T. K. Lin, C. W. Liou, P. W. Wang, J. B. Chen, F. Y. Kuo, C. C. Huang, Y. M. Chou and J. H. Chuang: Early transcriptional deregulation of hepatic mitochondrial biogenesis and its consequent effects on murine cholestatic liver injury, Apoptosis 14, 890-899 (2009)

17. A. Arduini, G. Serviddio, J. Escobar, A. M. Tormos, F. Bellanti, J. Vina, M. Monsalve and J. Sastre: Mitochondrial Biogenesis Fails in Secondary Biliary Cirrhosis in Rats Leading to Mitochondrial Dna Depletion and Deletions, Am J Physiol Gastrointest Liver Physiol (2011)

18. G. Serviddio, J. Pereda, F. V. Pallardo, J. Carretero, C. Borras, J. Cutrin, G. Vendemiale, G. Poli, J. Vina and J. Sastre: Ursodeoxycholic acid protects against secondary biliary cirrhosis in rats by preventing mitochondrial oxidative stress, Hepatology 39, 711-720 (2004)

19. S. Krahenbuhl, C. Talos, S. Fischer and J. Reichen: Toxicity of bile acids on the electron transport chain of isolated rat liver mitochondria, Hepatology 19, 471-479 (1994)

20. C. Lang, S. Berardi, M. Schafer, D. Serra, F. G. Hegardt, L. Krahenbuhl and S. Krahenbuhl: Impaired ketogenesis is a major mechanism for disturbed hepatic fatty acid metabolism in rats with long-term cholestasis and after relief of biliary obstruction, $\mathrm{J}$ Hepatol 37, 564-571 (2002)

21. C. Lang, M. Schafer, D. Serra, F. Hegardt, L. Krahenbuhl and S. Krahenbuhl: Impaired hepatic fatty acid oxidation in rats with short-term cholestasis: characterization and mechanism, J Lipid Res 42, 22-30 (2001)

22. L. Krahenbuhl, C. Talos, J. Reichen and S. Krahenbuhl: Progressive decrease in tissue glycogen content in rats with longterm cholestasis, Hepatology 24, 902-907 (1996) 
23. B. L. Copple, H. Jaeschke and C. D. Klaassen: Oxidative stress and the pathogenesis of cholestasis, Semin Liver Dis 30, 195204 (2010)

24. G. Poli, Pathogenesis of liver fibrosis: role of oxidative stress, Mol Aspects Med 21, 49-98 (2000)

25. S. Krahenbuhl and E. P. Brass: Fuel homeostasis and carnitine metabolism in rats with secondary biliary cirrhosis, Hepatology 14, 927-934 (1991)

26. O. E. Owen, F. A. Reichle, M. A. Mozzoli, T. Kreulen, M. S. Patel, I. B. Elfenbein, M. Golsorkhi, K. H. Chang, N. S. Rao, H. S. Sue and G. Boden: Hepatic, gut, and renal substrate flux rates in patients with hepatic cirrhosis, J Clin Invest 68, $240-252$ (1981)

27. H. Malhi, G. J. Gores and J. J. Lemasters: Apoptosis and necrosis in the liver: a tale of two deaths? Hepatology 43, S31-44 (2006)

28. A. F. Attili, M. Angelico, A. Cantafora, D. Alvaro and L. Capocaccia: Bile acid-induced liver toxicity: relation to the hydrophobic-hydrophilic balance of bile acids, Med Hypotheses 19, 57-69 (1986)

29. J. R. Spivey, S. F. Bronk and G. J. Gores: Glycochenodeoxycholate-induced lethal hepatocellular injury in rat hepatocytes. Role of ATP depletion and cytosolic free calcium, J Clin Invest 92, 17-24 (1993)

30. A. P. Rolo, P. J. Oliveira, A. J. Moreno and C. M. Palmeira: Bile acids affect liver mitochondrial bioenergetics: possible relevance for cholestasis therapy, Toxicol Sci 57, 177-185 (2000)

31. K. Koyama, K. Ito, K. Ouchi and T. Sato: Mitochondrial function of rat liver in biliary obstruction, Tohoku J Exp Med 131, 59-69 (1980)

32. I. A. Fraser, P. Shaffer, S. V. Tuttle, M. A. Lessler, E. C. Ellison and L. C. Carey: Hepatic recovery after biliary decompression of experimental obstructive jaundice, Am J Surg 158, 423-427 (1989)

33. R. N. Younes, R. S. Poggetti, B. Fontes, M. M. Itinoshe, V. M. Yoshida, M. E. Carvalho and D. Birolini: Obstructive jaundice induces early depression of mitochondrial respiration in rat hepatocytes, Acta Cir Bras 22, 251-254 (2007)

34. L. Enochsson, B. Isaksson, L. Strommer, C. Erlanson-Albertsson and J. Permert: Bile duct obstruction is associated with early postoperative upregulation of liver uncoupling protein-2 and reduced circulating glucose concentration in the rat, Nutrition 26, 405-410 (2010)

35. K. Ozawa, O. Kitamura, Y. Yamaoka, T. Mizukami and T. Kamano: Role of portal blood on the enhancement of liver mitochondrial metabolism, Am J Surg 124, 16-20 (1972)

36. S. Krahenbuhl, S. Krahenbuhl-Glauser, J. Stucki, P. Gehr and J. Reichen: Stereological and functional analysis of liver mitochondria from rats with secondary biliary cirrhosis: impaired mitochondrial metabolism and increased mitochondrial content per hepatocyte, Hepatology 15, 1167-1172 (1992)

37. Y. Asanuma and K. Koyama: Effect of nonbiological hepatic assist on the mitochondrial function of the liver: basic consideration, Artif Organs 18, 367-370 (1994)

38. M. Kanai, M. Tanaka, Y. Nimura, M. Nagino, T. Katoh and T. Ozawa: Mechanism of adaptive increase of respiratory enzymes in rat liver mitochondria during obstructive jaundice, Biochem Int 23, 1165-1173 (1991)

39. S. Krahenbuhl, J. Stucki and J. Reichen: Reduced activity of the electron transport chain in liver mitochondria isolated from rats with secondary biliary cirrhosis, Hepatology 15, 1160-1166 (1992)

40. M. Kanai, M. Tanaka, Y. Nimura, M. Nagino, T. Katoh and T. Ozawa: Mitochondrial dysfunction in the non-obstructed lobe of rat liver after selective biliary obstruction, Hepatogastroenterology 39, 385-391 (1992)

41. R. Kemp, O. Castro-e-Silva, J. S. Santos, A. K. Sankarankutty, R. B. Correa, C. F. Baldo, M. E. Souza and M. C. Jordani: Evaluation of the mitochondrial respiration of cardiac myocytes in rats submitted to mechanical bile duct obstruction, Acta Cir Bras 23 Suppl 1, 66-71; discussion 71 (2008)

42. M. B. Hock and A. Kralli: Transcriptional control of mitochondrial biogenesis and function, Annu Rev Physiol 71, 177-203 (2009) 
43. D. J. Pagliarini, S. E. Calvo, B. Chang, S. A. Sheth, S. B. Vafai, S. E. Ong, G. A. Walford, C. Sugiana, A. Boneh, W. K. Chen, D. E. Hill, M. Vidal, J. G. Evans, D. R. Thorburn, S. A. Carr and V. K. Mootha: A mitochondrial protein compendium elucidates complex I disease biology, Cell 134, 112-123 (2008)

44. R. C. Scarpulla, Nuclear activators and coactivators in mammalian mitochondrial biogenesis, Biochim Biophys Acta 1576, 1$14(2002)$

45. M. Falkenberg, M. Gaspari, A. Rantanen, A. Trifunovic, N. G. Larsson and C. M. Gustafsson: Mitochondrial transcription factors B1 and B2 activate transcription of human mtDNA, Nat Genet 31, 289-294 (2002)

46. D. Litonin, M. Sologub, Y. Shi, M. Savkina, M. Anikin, M. Falkenberg, C. M. Gustafsson and D. Temiakov: Human mitochondrial transcription revisited: only TFAM and TFB2M are required for transcription of the mitochondrial genes in vitro, $\mathrm{J}$ Biol Chem 285, 18129-18133 (2010)

47. M. Forestier, M. Solioz, F. Isbeki, C. Talos, J. Reichen and S. Krahenbuhl: Hepatic mitochondrial proliferation in rats with secondary biliary cirrhosis: time course and mechanisms, Hepatology 26, 386-391 (1997)

48. M. J. Baker, A. E. Frazier, J. M. Gulbis and M. T. Ryan: Mitochondrial protein-import machinery: correlating structure with function, Trends Cell Biol 17, 456-464 (2007)

49. J. Martin, K. Mahlke and N. Pfanner: Role of an energized inner membrane in mitochondrial protein import. Delta psi drives the movement of presequences, J Biol Chem 266, 18051-18057 (1991)

50. O. Schmidt, N. Pfanner and C. Meisinger: Mitochondrial protein import: from proteomics to functional mechanisms, Nat Rev Mol Cell Biol 11, 655-667 (2010)

51. T. Lithgow, B. S. Glick and G. Schatz: The protein import receptor of mitochondria, Trends Biochem Sci 20, 98-101 (1995)

52. K. Yamano, Y. Yatsukawa, M. Esaki, A. E. Hobbs, R. E. Jensen and T. Endo: Tom 20 and Tom 22 share the common signal recognition pathway in mitochondrial protein import, J Biol Chem 283, 3799-3807 (2008)

53. H. Yamamoto, K. Fukui, H. Takahashi, S. Kitamura, T. Shiota, K. Terao, M. Uchida, M. Esaki, S. Nishikawa, T. Yoshihisa, K. Yamano and T. Endo: Roles of Tom70 in import of presequence-containing mitochondrial proteins, J Biol Chem 284, 31635$31646(2009)$

54. C. K. Fox, A. Furtwaengler, R. R. Nepomuceno, O. M. Martinez and S. M. Krams: Apoptotic pathways in primary biliary cirrhosis and autoimmune hepatitis, Liver 21, 272-279 (2001)

55. A. Floreani, M. Guido, M. Bortolami, G. Della Zentil, C. Venturi, N. Pennelli and R. Naccarato: Relationship between apoptosis, tumour necrosis factor, and cell proliferation in chronic cholestasis, Dig Liver Dis 33, 570-575 (2001)

56. P. Papakyriakou, M. Tzardi, V. Valatas, P. Kanavaros, E. Karydi, G. Notas, C. Xidakis and E. Kouroumalis: Apoptosis and apoptosis related proteins in chronic viral liver disease, Apoptosis 7, 133-141 (2002)

57. Z. Jiang, Y. Liu, L. Savas, L. Smith, H. Bonkovsky, S. Baker and B. Banner: Frequency and distribution of DNA fragmentation as a marker of cell death in chronic liver diseases, Virchows Arch 431, 189-194 (1997)

58. G. Kroemer, W. S. El-Deiry, P. Golstein, M. E. Peter, D. Vaux, P. Vandenabeele, B. Zhivotovsky, M. V. Blagosklonny, W. Malorni, R. A. Knight, M. Piacentini, S. Nagata, G. Melino and Nomenclature Committee on Cell Death: Classification of cell death: recommendations of the Nomenclature Committee on Cell Death, Cell Death Differ 12 Suppl 2, 1463-1467 (2005)

59. H. Walczak and T. L. Haas: Biochemical analysis of the native TRAIL death-inducing signaling complex, Methods Mol Biol 414, 221-239 (2008)

60. X. M. Yin, K. Wang, A. Gross, Y. Zhao, S. Zinkel, B. Klocke, K. A. Roth and S. J. Korsmeyer: Bid-deficient mice are resistant to Fas-induced hepatocellular apoptosis, Nature 400, 886-891 (1999)

61. Y. Zhao, S. Li, E. E. Childs, D. K. Kuharsky and X. M. Yin: Activation of pro-death Bcl-2 family proteins and mitochondria apoptosis pathway in tumor necrosis factor-alpha-induced liver injury, J Biol Chem 276, 27432-27440 (2001) 
62. H. Jaeschke and M. L. Bajt: Regulation of apoptotic signaling pathways in hepatocytes in vivo, Hepatology 37, $942-945$ (2003)

63. P. J. Jost, S. Grabow, D. Gray, M. D. McKenzie, U. Nachbur, D. C. Huang, P. Bouillet, H. E. Thomas, C. Borner, J. Silke, A. Strasser and T. Kaufmann: XIAP discriminates between type I and type II FAS-induced apoptosis, Nature 460, 1035-1039 (2009)

64. S. Schungel, L. E. Buitrago-Molina, P. Nalapareddy, M. Lebofsky, M. P. Manns, H. Jaeschke, A. Gross and A. Vogel: The strength of the Fas ligand signal determines whether hepatocytes act as type 1 or type 2 cells in murine livers, Hepatology 50, $1558-1566$ (2009)

65. D. Walter, K. Schmich, S. Vogel, R. Pick, T. Kaufmann, F. C. Hochmuth, A. Haber, K. Neubert, S. McNelly, F. von Weizsacker, I. Merfort, U. Maurer, A. Strasser and C. Borner: Switch from type II to I Fas/CD95 death signaling on in vitro culturing of primary hepatocytes, Hepatology 48, 1942-1953 (2008)

66. M. H. Schoemaker, W. M. Gommans, L. Conde de la Rosa, M. Homan, P. Klok, C. Trautwein, H. van Goor, K. Poelstra, H. J. Haisma, P. L. Jansen and H. Moshage: Resistance of rat hepatocytes against bile acid-induced apoptosis in cholestatic liver injury is due to nuclear factor-kappa B activation, J Hepatol 39, 153-161 (2003)

67. H. Miyoshi, C. Rust, M. E. Guicciardi and G. J. Gores: NF-kappaB is activated in cholestasis and functions to reduce liver injury, Am J Pathol 158, 967-975 (2001)

68. H. Miyoshi, C. Rust, P. J. Roberts, L. J. Burgart and G. J. Gores: Hepatocyte apoptosis after bile duct ligation in the mouse involves Fas, Gastroenterology 117, 669-677 (1999)

69. S. H. Oh, K. J. Yun, J. X. Nan, D. H. Sohn and B. H. Lee: Changes in expression and immunolocalization of protein associated with toxic bile salts-induced apoptosis in rat hepatocytes, Arch Toxicol 77, 110-115 (2003)

70. A. P. Rolo, P. J. Oliveira, A. J. Moreno and C. M. Palmeira: Chenodeoxycholate is a potent inducer of the permeability transition pore in rat liver mitochondria, Biosci Rep 21, 73-80 (2001)

71. R. Botla, J. R. Spivey, H. Aguilar, S. F. Bronk and G. J. Gores: Ursodeoxycholate (UDCA) inhibits the mitochondrial membrane permeability transition induced by glycochenodeoxycholate: a mechanism of UDCA cytoprotection, J Pharmacol Exp Ther 272, 930-938 (1995)

72. C. M. Rodrigues, G. Fan, X. Ma, B. T. Kren and C. J. Steer: A novel role for ursodeoxycholic acid in inhibiting apoptosis by modulating mitochondrial membrane perturbation, J Clin Invest 101, 2790-2799 (1998)

73. C. M. Rodrigues, G. Fan, P. Y. Wong, B. T. Kren and C. J. Steer: Ursodeoxycholic acid may inhibit deoxycholic acidinduced apoptosis by modulating mitochondrial transmembrane potential and reactive oxygen species production, Mol Med 4, $165-178$ (1998)

74. B. Yerushalmi, R. Dahl, M. W. Devereaux, E. Gumpricht and R. J. Sokol: Bile acid-induced rat hepatocyte apoptosis is inhibited by antioxidants and blockers of the mitochondrial permeability transition, Hepatology 33, 616-626 (2001)

75. H. Higuchi, H. Miyoshi, S. F. Bronk, H. Zhang, N. Dean and G. J. Gores: Bid antisense attenuates bile acid-induced apoptosis and cholestatic liver injury, J Pharmacol Exp Ther 299, 866-873 (2001)

76. A. P. Rolo, C. M. Palmeira, J. M. Holy and K. B. Wallace: Role of mitochondrial dysfunction in combined bile acid-induced cytotoxicity: the switch between apoptosis and necrosis, Toxicol Sci 79, 196-204 (2004)

77. W. A. Faubion, M. E. Guicciardi, H. Miyoshi, S. F. Bronk, P. J. Roberts, P. A. Svingen, S. H. Kaufmann and G. J. Gores: Toxic bile salts induce rodent hepatocyte apoptosis via direct activation of Fas, J Clin Invest 103, 137-145 (1999)

78. H. Greim, D. Trulzsch, P. Czygan, J. Rudick, F. Hutterer, F. Schaffner and H. Popper: Mechanism of cholestasis. 6. Bile acids in human livers with or without biliary obstruction, Gastroenterology 63, 846-850 (1972)

79. H. Greim, D. Trulzsch, J. Roboz, K. Dressler, P. Czygan, F. Hutterer, F. Schaffner and H. Popper: Mechanism of cholestasis. 5. Bile acids in normal rat livers and in those after bile duct ligation, Gastroenterology 63, 837-845 (1972)

80. A. Kahraman, F. J. Barreyro, S. F. Bronk, N. W. Werneburg, J. L. Mott, Y. Akazawa, H. C. Masuoka, C. L. Howe and G. J. Gores: TRAIL mediates liver injury by the innate immune system in the bile duct-ligated mouse, Hepatology 47, 1317-1330 (2008) 
81. T. Sodeman, S. F. Bronk, P. J. Roberts, H. Miyoshi and G. J. Gores: Bile salts mediate hepatocyte apoptosis by increasing cell surface trafficking of Fas, Am J Physiol Gastrointest Liver Physiol 278, G992-9 (2000)

82. H. Higuchi, J. H. Yoon, A. Grambihler, N. Werneburg, S. F. Bronk and G. J. Gores: Bile acids stimulate cFLIP phosphorylation enhancing TRAIL-mediated apoptosis, J Biol Chem 278, 454-461 (2003)

83. H. Higuchi, A. Grambihler, A. Canbay, S. F. Bronk and G. J. Gores: Bile acids up-regulate death receptor 5/TRAIL-receptor 2 expression via a c-Jun N-terminal kinase-dependent pathway involving Sp1, J Biol Chem 279, 51-60 (2004)

84. H. Higuchi, S. F. Bronk, M. Taniai, A. Canbay and G. J. Gores: Cholestasis increases tumor necrosis factor-related apoptotisinducing ligand (TRAIL)-R2/DR5 expression and sensitizes the liver to TRAIL-mediated cytotoxicity, J Pharmacol Exp Ther $303,461-467$ (2002)

85. J. S. Gujral, J. Liu, A. Farhood and H. Jaeschke: Reduced oncotic necrosis in Fas receptor-deficient C57BL/6J-lpr mice after bile duct ligation, Hepatology 40, 998-1007 (2004)

86. J. J. Maher, What doesn't kill you makes you stronger: how hepatocytes survive prolonged cholestasis, Hepatology 39, 1141$1143(2004)$

87. M. J. Lieser, J. Park, S. Natori, B. A. Jones, S. F. Bronk and G. J. Gores: Cholestasis confers resistance to the rat liver mitochondrial permeability transition, Gastroenterology 115, 693-701 (1998)

88. A. Vogel, J. E. Aslan, H. Willenbring, C. Klein, M. Finegold, H. Mount, G. Thomas and M. Grompe: Sustained phosphorylation of $\mathrm{Bid}$ is a marker for resistance to Fas-induced apoptosis during chronic liver diseases, Gastroenterology 130 , 104-119 (2006)

89. C. M. Payne, C. L. Crowley-Weber, K. Dvorak, C. Bernstein, H. Bernstein, H. Holubec, C. Crowley and H. Garewal: Mitochondrial perturbation attenuates bile acid-induced cytotoxicity, Cell Biol Toxicol 21, 215-231 (2005)

90. S. Faouzi, B. E. Burckhardt, J. C. Hanson, C. B. Campe, L. W. Schrum, R. A. Rippe and J. J. Maher: Anti-Fas induces hepatic chemokines and promotes inflammation by an NF-kappa B-independent, caspase-3-dependent pathway, J Biol Chem 276, 49077-49082 (2001)

91. A. Canbay, P. Taimr, N. Torok, H. Higuchi, S. Friedman and G. J. Gores: Apoptotic body engulfment by a human stellate cell line is profibrogenic, Lab Invest 83, 655-663 (2003)

92. A. Canbay, A. E. Feldstein, H. Higuchi, N. Werneburg, A. Grambihler, S. F. Bronk and G. J. Gores: Kupffer cell engulfment of apoptotic bodies stimulates death ligand and cytokine expression, Hepatology 38, 1188-1198 (2003)

93. H. L. Reeves and S. L. Friedman: Activation of hepatic stellate cells--a key issue in liver fibrosis, Front Biosci 7, d808-26 (2002)

94. A. Canbay, S. Friedman and G. J. Gores: Apoptosis: the nexus of liver injury and fibrosis, Hepatology 39, 273-278 (2004)

95. G. Vendemiale, I. Grattagliano, L. Lupo, V. Memeo and E. Altomare: Hepatic oxidative alterations in patients with extrahepatic cholestasis. Effect of surgical drainage, J Hepatol 37, 601-605 (2002)

96. A. Aboutwerat, P. W. Pemberton, A. Smith, P. C. Burrows, R. F. McMahon, S. K. Jain and T. W. Warnes: Oxidant stress is a significant feature of primary biliary cirrhosis, Biochim Biophys Acta 1637, 142-150 (2003)

97. K. Kawata, Y. Kobayashi, K. Souda, K. Kawamura, S. Sumiyoshi, Y. Takahashi, H. Noritake, S. Watanabe, T. Suehiro and H. Nakamura: Enhanced hepatic Nrf2 activation after ursodeoxycholic acid treatment in patients with primary biliary cirrhosis, Antioxid Redox Signal 13, 259-268 (2010)

98. S. Sakaguchi and S. Furusawa: Oxidative stress and septic shock: metabolic aspects of oxygen-derived free radicals generated in the liver during endotoxemia, FEMS Immunol Med Microbiol 47, 167-177 (2006)

99. P. Ljubuncic, Z. Tanne and A. Bomzon: Evidence of a systemic phenomenon for oxidative stress in cholestatic liver disease, Gut 47, 710-716 (2000) 
100. H. Sies and E. Cadenas: Oxidative stress: damage to intact cells and organs, Philos Trans R Soc Lond B Biol Sci 311, 617$631(1985)$

101. N. Alptekin, G. Mehmetcik, M. Uysal and G. Aykac-toker: Evidence for oxidative stress in the hepatic mitochondria of bile duct ligated rats, Pharmacol Res 36, 243-247 (1997)

102. E. Purucker, R. Winograd, E. Roeb and S. Matern: Glutathione status in liver and plasma during development of biliary cirrhosis after bile duct ligation, Res Exp Med (Berl) 198, 167-174 (1998)

103. Y. T. Huang, Y. C. Hsu, C. J. Chen, C. T. Liu and Y. H. Wei: Oxidative-stress-related changes in the livers of bile-ductligated rats, J Biomed Sci 10, 170-178 (2003)

104. H. Yang, K. Ko, M. Xia, T. W. Li, P. Oh, J. Li and S. C. Lu: Induction of avian musculoaponeurotic fibrosarcoma proteins by toxic bile acid inhibits expression of glutathione synthetic enzymes and contributes to cholestatic liver injury in mice, Hepatology 51, 1291-1301 (2010)

105. A. Colell, C. Garcia-Ruiz, M. Miranda, E. Ardite, M. Mari, A. Morales, F. Corrales, N. Kaplowitz and J. C. FernandezCheca: Selective glutathione depletion of mitochondria by ethanol sensitizes hepatocytes to tumor necrosis factor, Gastroenterology 115, 1541-1551 (1998)

106. S. Krahenbuhl, C. Talos, B. H. Lauterburg and J. Reichen: Reduced antioxidative capacity in liver mitochondria from bile duct ligated rats, Hepatology 22, 607-612 (1995)

107. R. J. Sokol, M. Devereaux and R. A. Khandwala: Effect of dietary lipid and vitamin E on mitochondrial lipid peroxidation and hepatic injury in the bile duct-ligated rat, J Lipid Res 32, 1349-1357 (1991)

108. T. Nguyen, P. Nioi and C. B. Pickett: The Nrf2-antioxidant response element signaling pathway and its activation by oxidative stress, J Biol Chem 284, 13291-13295 (2009)

109. K. Okada, J. Shoda, K. Taguchi, J. M. Maher, K. Ishizaki, Y. Inoue, M. Ohtsuki, N. Goto, K. Takeda, H. Utsunomiya, K. Oda, E. Warabi, T. Ishii, K. Osaka, I. Hyodo and M. Yamamoto: Ursodeoxycholic acid stimulates Nrf2-mediated hepatocellular transport, detoxification, and antioxidative stress systems in mice, Am J Physiol Gastrointest Liver Physiol 295, G735-47 (2008)

110. S. Arisawa, K. Ishida, N. Kameyama, J. Ueyama, A. Hattori, Y. Tatsumi, H. Hayashi, M. Yano, K. Hayashi, Y. Katano, H. Goto, K. Takagi and S. Wakusawa: Ursodeoxycholic acid induces glutathione synthesis through activation of PI3K/Akt pathway in HepG2 cells, Biochem Pharmacol 77, 858-866 (2009)

111. R. J. Sokol, J. M. McKim Jr, M. C. Goff, S. Z. Ruyle, M. W. Devereaux, D. Han, L. Packer and G. Everson: Vitamin E reduces oxidant injury to mitochondria and the hepatotoxicity of taurochenodeoxycholic acid in the rat, Gastroenterology 114 , 164-174 (1998)

112. R. J. Sokol, M. S. Straka, R. Dahl, M. W. Devereaux, B. Yerushalmi, E. Gumpricht, N. Elkins and G. Everson: Role of oxidant stress in the permeability transition induced in rat hepatic mitochondria by hydrophobic bile acids, Pediatr Res 49, 519$531(2001)$

113. Z. Zhong, M. Froh, M. D. Wheeler, O. Smutney, T. G. Lehmann and R. G. Thurman: Viral gene delivery of superoxide dismutase attenuates experimental cholestasis-induced liver fibrosis in the rat, Gene Ther 9, 183-191 (2002)

114. R. J. Sokol, M. W. Devereaux and R. Khandwala: Effect of oxypurinol, a xanthine oxidase inhibitor, on hepatic injury in the bile duct-ligated rat, Pediatr Res 44, 397-401 (1998)

115. M. R. Ebrahimkhani, H. Sadeghipour, M. Dehghani, S. Kiani, S. Payabvash, K. Riazi, H. Honar, P. Pasalar, N. Mirazi, M. Amanlou, H. Farsam and A. R. Dehpour: Homocysteine alterations in experimental cholestasis and its subsequent cirrhosis, Life Sci 76, 2497-2512 (2005)

116. V. Baron and P. Muriel: Role of glutathione, lipid peroxidation and antioxidants on acute bile-duct obstruction in the rat, Biochim Biophys Acta 1472, 173-180 (1999)

117. Y. Fang, S. I. Han, C. Mitchell, S. Gupta, E. Studer, S. Grant, P. B. Hylemon and P. Dent: Bile acids induce mitochondrial ROS, which promote activation of receptor tyrosine kinases and signaling pathways in rat hepatocytes, Hepatology 40, 961-971 (2004) 
118. L. Qiao, A. Yacoub, E. Studer, S. Gupta, X. Y. Pei, S. Grant, P. B. Hylemon and P. Dent: Inhibition of the MAPK and PI3K pathways enhances UDCA-induced apoptosis in primary rodent hepatocytes, Hepatology 35, 779-789 (2002)

119. L. Qiao, E. Studer, K. Leach, R. McKinstry, S. Gupta, R. Decker, R. Kukreja, K. Valerie, P. Nagarkatti, W. El Deiry, J. Molkentin, R. Schmidt-Ullrich, P. B. Fisher, S. Grant, P. B. Hylemon and P. Dent: Deoxycholic acid (DCA) causes ligandindependent activation of epidermal growth factor receptor (EGFR) and FAS receptor in primary hepatocytes: inhibition of EGFR/mitogen-activated protein kinase-signaling module enhances DCA-induced apoptosis, Mol Biol Cell 12, $2629-2645$ (2001)

120. E. Chavez, R. Moreno-Sanchez, M. E. Torres-Marquez, C. Zazueta, C. Bravo, S. Rodriquez-Enriquez, C. Garcia, J. S. Rodriguez and F. Martinez: Modulation of matrix Ca2+ content by the ADP/ATP carrier in brown adipose tissue mitochondria. Influence of membrane lipid composition, J Bioenerg Biomembr 28, 69-76 (1996)

121. E. Novo and M. Parola: Redox mechanisms in hepatic chronic wound healing and fibrogenesis, Fibrogenesis Tissue Repair $1,5(2008)$

122. H. B. Suliman, M. S. Carraway, K. E. Welty-Wolf, A. R. Whorton and C. A. Piantadosi: Lipopolysaccharide stimulates mitochondrial biogenesis via activation of nuclear respiratory factor-1, J Biol Chem 278, 41510-41518 (2003)

123. H. B. Suliman, M. S. Carraway and C. A. Piantadosi: Postlipopolysaccharide oxidative damage of mitochondrial DNA, Am J Respir Crit Care Med 167, 570-579 (2003)

124. M. G. Roma and E. J. Sanchez Pozzi: Oxidative stress: a radical way to stop making bile, Ann Hepatol 7, 16-33 (2008)

125. S. Sekine, K. Ito and T. Horie: Canalicular Mrp2 localization is reversibly regulated by the intracellular redox status, Am J Physiol Gastrointest Liver Physiol 295, G1035-41 (2008)

126. J. S. Gujral, A. Farhood, M. L. Bajt and H. Jaeschke: Neutrophils aggravate acute liver injury during obstructive cholestasis in bile duct-ligated mice, Hepatology 38, 355-363 (2003)

127. A. Bohan, W. S. Chen, L. A. Denson, M. A. Held and J. L. Boyer: Tumor necrosis factor alpha-dependent up-regulation of Lrh-1 and Mrp3(Abcc3) reduces liver injury in obstructive cholestasis, J Biol Chem 278, 36688-36698 (2003)

128. S. Gehring, E. M. Dickson, M. E. San Martin, N. van Rooijen, E. F. Papa, M. W. Harty, T. F. Tracy Jr and S. H. Gregory: Kupffer cells abrogate cholestatic liver injury in mice, Gastroenterology 130, 810-822 (2006)

129. S. L. Friedman, Mechanisms of hepatic fibrogenesis, Gastroenterology 134, 1655-1669 (2008)

130. H. Jaeschke, G. J. Gores, A. I. Cederbaum, J. A. Hinson, D. Pessayre and J. J. Lemasters: Mechanisms of hepatotoxicity, Toxicol Sci 65, 166-176 (2002)

131. J. A. Kennedy, W. D. Clements, S. J. Kirk, M. D. McCaigue, G. R. Campbell, P. J. Erwin, M. I. Halliday and B. J. Rowlands: Characterization of the Kupffer cell response to exogenous endotoxin in a rodent model of obstructive jaundice, Br $\mathrm{J}$ Surg 86, 628-633 (1999)

132. M. Trauner, P. Fickert and R. E. Stauber: Inflammation-induced cholestasis, J Gastroenterol Hepatol 14, 946-959 (1999)

133. J. F. Whiting, R. M. Green, A. B. Rosenbluth and J. L. Gollan: Tumor necrosis factor-alpha decreases hepatocyte bile salt uptake and mediates endotoxin-induced cholestasis, Hepatology 22, 1273-1278 (1995)

134. R. H. Moseley, W. Wang, H. Takeda, K. Lown, L. Shick, M. Ananthanarayanan and F. J. Suchy: Effect of endotoxin on bile acid transport in rat liver: a potential model for sepsis-associated cholestasis, Am J Physiol 271, G137-46 (1996)

135. D. Han, M. D. Ybanez, S. Ahmadi, K. Yeh and N. Kaplowitz: Redox regulation of tumor necrosis factor signaling, Antioxid Redox Signal 11, 2245-2263 (2009)

136. W. S. Lee and R. J. Sokol: Mitochondrial hepatopathies: advances in genetics and pathogenesis, Hepatology 45, 1555-1565 (2007)

137. W. R. Treem and R. J. Sokol: Disorders of the mitochondria, Semin Liver Dis 18, 237-253 (1998)

138. R. J. Sokol and W. R. Treem: Mitochondria and childhood liver diseases, J Pediatr Gastroenterol Nutr 28, 4-16 (1999) 
139. D. R. Johns, Seminars in medicine of the Beth Israel Hospital, Boston. Mitochondrial DNA and disease, N Engl J Med 333, 638-644 (1995)

140. I. Goncalves, D. Hermans, D. Chretien, P. Rustin, A. Munnich, J. M. Saudubray, F. Van Hoof, R. Reding, J. de Ville de Goyet and J. B. Otte: Mitochondrial respiratory chain defect: a new etiology for neonatal cholestasis and early liver insufficiency, J Hepatol 23, 290-294 (1995)

141. M. Komura, K. Chijiiwa, T. Naito, N. Kameoka, H. Yamashita, K. Yamaguchi, S. Kuroki and M. Tanaka: Sequential changes of energy charge, lipoperoxide level, and DNA synthesis rate of the liver following biliary obstruction in rats, J Surg Res $61,503-508(1996)$

142. L. Krahenbuhl, M. Schafer and S. Krahenbuhl: Reversibility of hepatic mitochondrial damage in rats with long-term cholestasis, J Hepatol 28, 1000-1007 (1998)

143. P. H. Ducluzeau, A. Lachaux, R. Bouvier, N. Streichenberger, G. Stepien and B. Mousson: Depletion of mitochondrial DNA associated with infantile cholestasis and progressive liver fibrosis, J Hepatol 30, 149-155 (1999)

144. R. C. Scarpulla, Transcriptional paradigms in mammalian mitochondrial biogenesis and function, Physiol Rev 88, $611-638$ (2008)

145. L. R. Hagey, D. L. Crombie, E. Espinosa, M. C. Carey, H. Igimi and A. F. Hofmann: Ursodeoxycholic acid in the Ursidae: biliary bile acids of bears, pandas, and related carnivores, J Lipid Res 34, 1911-1917 (1993)

146. T. Ikegami and Y. Matsuzaki: Ursodeoxycholic acid: Mechanism of action and novel clinical applications, Hepatol Res 38 , $123-131(2008)$

147. C. M. Rodrigues, X. Ma, C. Linehan-Stieers, G. Fan, B. T. Kren and C. J. Steer: Ursodeoxycholic acid prevents cytochrome c release in apoptosis by inhibiting mitochondrial membrane depolarization and channel formation, Cell Death Differ 6, 842-854 (1999)

148. M. H. Schoemaker, L. Conde de la Rosa, M. Buist-Homan, T. E. Vrenken, R. Havinga, K. Poelstra, H. J. Haisma, P. L. Jansen and H. Moshage: Tauroursodeoxycholic acid protects rat hepatocytes from bile acid-induced apoptosis via activation of survival pathways, Hepatology 39, 1563-1573 (2004)

149. Y. Calmus and R. Poupon: Ursodeoxycholic acid (UDCA) in the treatment of chronic cholestatic diseases, Biochimie 73 , $1335-1338(1991)$

150. Y. Calmus, P. Gane, P. Rouger and R. Poupon: Hepatic expression of class I and class II major histocompatibility complex molecules in primary biliary cirrhosis: effect of ursodeoxycholic acid, Hepatology 11, 12-15 (1990)

151. C. M. Van Nieuwkerk, R. P. Elferink, A. K. Groen, R. Ottenhoff, G. N. Tytgat, K. P. Dingemans, M. A. Van Den Bergh Weerman and G. J. Offerhaus: Effects of Ursodeoxycholate and cholate feeding on liver disease in FVB mice with a disrupted mdr2 P-glycoprotein gene, Gastroenterology 111, 165-171 (1996)

152. U. Beuers, M. Bilzer, A. Chittattu, G. A. Kullak-Ublick, D. Keppler, G. Paumgartner and F. Dombrowski: Tauroursodeoxycholic acid inserts the apical conjugate export pump, Mrp2, into canalicular membranes and stimulates organic anion secretion by protein kinase C-dependent mechanisms in cholestatic rat liver, Hepatology 33, 1206-1216 (2001)

153. R. P. Jazrawi, J. S. de Caestecker, P. M. Goggin, A. J. Britten, A. E. Joseph, J. D. Maxwell and T. C. Northfield: Kinetics of hepatic bile acid handling in cholestatic liver disease: effect of ursodeoxycholic acid, Gastroenterology 106, 134-142 (1994)

154. R. Wimmer, S. Hohenester, T. Pusl, G. U. Denk, C. Rust and U. Beuers: Tauroursodeoxycholic acid exerts anticholestatic effects by a cooperative cPKC alpha-/PKA-dependent mechanism in rat liver, Gut 57, 1448-1454 (2008)

155. C. R. Webster and M. S. Anwer: Cyclic adenosine monophosphate-mediated protection against bile acid-induced apoptosis in cultured rat hepatocytes, Hepatology 27, 1324-1331 (1998)

156. M. Marzioni, H. Francis, A. Benedetti, Y. Ueno, G. Fava, J. Venter, R. Reichenbach, M. G. Mancino, R. Summers, G. Alpini and S. Glaser: Ca2+-dependent cytoprotective effects of ursodeoxycholic and tauroursodeoxycholic acid on the biliary epithelium in a rat model of cholestasis and loss of bile ducts, Am J Pathol 168, 398-409 (2006) 
157. H. Mitsuyoshi, T. Nakashima, Y. Sumida, T. Yoh, Y. Nakajima, H. Ishikawa, K. Inaba, Y. Sakamoto, T. Okanoue and K. Kashima: Ursodeoxycholic acid protects hepatocytes against oxidative injury via induction of antioxidants, Biochem Biophys Res Commun 263, 537-542 (1999)

158. R. A. Smith, C. M. Porteous, C. V. Coulter and M. P. Murphy: Selective targeting of an antioxidant to mitochondria, Eur J Biochem 263, 709-716 (1999)

159. M. P. Murphy and R. A. Smith: Targeting antioxidants to mitochondria by conjugation to lipophilic cations, Annu Rev Pharmacol Toxicol 47, 629-656 (2007)

160. K. Zhao, G. M. Zhao, D. Wu, Y. Soong, A. V. Birk, P. W. Schiller and H. H. Szeto: Cell-permeable peptide antioxidants targeted to inner mitochondrial membrane inhibit mitochondrial swelling, oxidative cell death, and reperfusion injury, J Biol Chem 279, 34682-34690 (2004)

161. M. F. Ross, G. F. Kelso, F. H. Blaikie, A. M. James, H. M. Cocheme, A. Filipovska, T. Da Ros, T. R. Hurd, R. A. Smith and M. P. Murphy: Lipophilic triphenylphosphonium cations as tools in mitochondrial bioenergetics and free radical biology, Biochemistry (Mosc) 70, 222-230 (2005)

162. G. F. Kelso, C. M. Porteous, C. V. Coulter, G. Hughes, W. K. Porteous, E. C. Ledgerwood, R. A. Smith and M. P. Murphy: Selective targeting of a redox-active ubiquinone to mitochondria within cells: antioxidant and antiapoptotic properties, J Biol Chem 276, 4588-4596 (2001)

163. J. Asin-Cayuela, A. R. Manas, A. M. James, R. A. Smith and M. P. Murphy: Fine-tuning the hydrophobicity of a mitochondria-targeted antioxidant, FEBS Lett 571, 9-16 (2004)

164. A. M. James, H. M. Cocheme, R. A. Smith and M. P. Murphy: Interactions of mitochondria-targeted and untargeted ubiquinones with the mitochondrial respiratory chain and reactive oxygen species. Implications for the use of exogenous ubiquinones as therapies and experimental tools, J Biol Chem 280, 21295-21312 (2005)

165. R. A. Smith, C. M. Porteous, A. M. Gane and M. P. Murphy: Delivery of bioactive molecules to mitochondria in vivo, Proc Natl Acad Sci U S A 100, 5407-5412 (2003)

166. S. Rodriguez-Cuenca, H. M. Cocheme, A. Logan, I. Abakumova, T. A. Prime, C. Rose, A. Vidal-Puig, A. C. Smith, D. C. Rubinsztein, I. M. Fearnley, B. A. Jones, S. Pope, S. J. Heales, B. Y. Lam, S. G. Neogi, I. McFarlane, A. M. James, R. A. Smith and M. P. Murphy: Consequences of long-term oral administration of the mitochondria-targeted antioxidant MitoQ to wild-type mice, Free Radic Biol Med 48, 161-172 (2010)

167. B. J. Snow, F. L. Rolfe, M. M. Lockhart, C. M. Frampton, J. D. O'Sullivan, V. Fung, R. A. Smith, M. P. Murphy, K. M. Taylor and Protect Study Group: A double-blind, placebo-controlled study to assess the mitochondria-targeted antioxidant MitoQ as a disease-modifying therapy in Parkinson's disease, Mov Disord 25, 1670-1674 (2010)

168. V. J. Adlam, J. C. Harrison, C. M. Porteous, A. M. James, R. A. Smith, M. P. Murphy and I. A. Sammut: Targeting an antioxidant to mitochondria decreases cardiac ischemia-reperfusion injury, FASEB J 19, 1088-1095 (2005)

169. J. Neuzil, B. S. Rayner, H. C. Lowe and P. K. Witting: Oxidative stress in myocardial ischaemia reperfusion injury: a renewed focus on a long-standing area of heart research, Redox Rep 10, 187-197 (2005)

170. D. Graham, N. N. Huynh, C. A. Hamilton, E. Beattie, R. A. Smith, H. M. Cocheme, M. P. Murphy and A. F. Dominiczak: Mitochondria-targeted antioxidant MitoQ10 improves endothelial function and attenuates cardiac hypertrophy, Hypertension 54, 322-328 (2009)

171. D. A. Lowes, B. M. Thottakam, N. R. Webster, M. P. Murphy and H. F. Galley: The mitochondria-targeted antioxidant MitoQ protects against organ damage in a lipopolysaccharide-peptidoglycan model of sepsis, Free Radic Biol Med 45, 15591565 (2008)

172. E. J. Gane, F. Weilert, D. W. Orr, G. F. Keogh, M. Gibson, M. M. Lockhart, C. M. Frampton, K. M. Taylor, R. A. Smith and M. P. Murphy: The mitochondria-targeted anti-oxidant mitoquinone decreases liver damage in a phase II study of hepatitis C patients, Liver Int 30, 1019-1026 (2010)

Abbreviations: A1/Bfl, BCL2-related protein A1; ALT, alanine aminotransferase; ARE, antioxidant response element; BAK, and/or BCL2-antagonist/killer 1 (BAK); BAX, BCL2-associated X protein (BAX); BCL-2, B-cell CLL/lymphoma 2; BDL, bile duct ligation; BID, BH3 interacting domain death agonist; CDCA, chenodeoxycholic acid; cFLIP/cFLAR, CASP8 and FADD- 
like apoptosis regulator; cIAP2, baculoviral IAP repeat containing 3; c-Maf, c-avian musculoaponeurotic fibrosarcoma; $\mathrm{Cu} / \mathrm{ZnSOD}$, copper/zinc superoxide dismutase; Cycs, cytochrome c, somatic; DCA, deoxycholic acid; DISC, death initiating signaling complex; DR, death receptor; ERK1/2 mitogen-activated protein kinase 1/2; ERR- a, estrogen related receptor a; ETC, electron transport chain; FADD, Fas (TNFRSF6)-associated via death domain; FAS/APO1/CD95, TNF receptor superfamily, member 6; FasL, Fas ligand; GABP-a, GA binding protein transcription factor, alpha subunit 60kDa; GADD45beta, DNAdamage-inducible protein beta; GCDC, glycochenodeoxycholate; GSH, reduced glutathione; GSSG, oxidized glutathione; Hepatitis C Virus, HCV; HSC, hepatic stellate cells; Hsp60, heat shock protein $60 \mathrm{kDa}$; iNOS, inducible nitric oxide synthase; $\mathrm{IkB}$, nuclear factor of kappa light polypeptide gene enhancer in B-cells inhibitor, alpha; JNK, mitogen-activated protein kinase 8 and 9; LCA, litocholic acid; LDL, low density lipoprotein; Lpr, lymphoproliferation; MafG, V-maf musculoaponeurotic fibrosarcoma oncogene homolog G; Mdr2, multidrug resistance 2; MEK1/2, mitogen-activated protein kinase kinase 1/2; MnSOD, manganese superoxide dismutase; MPT, mitochondrial permeability transition; Mrp2, multidrug resistance-associated protein 2; mtDNA, mitochondrial DNA; nDNA, nuclear DNA; NF-kB, nuclear factor-kappa B; NRF-1, nuclear respiratory factor 1; Nrf2, nuclear factor, erythroid derived 2, like 2; NRF-2, nuclear respiratory factor 2; PBC, primary biliary cirrhosis; P:O ratio, relationship between ATP synthesis and oxygen consumption; PBDL, partial bile duct ligation; PGC-1a, peroxisome proliferator activated receptor $\mathrm{g}$ coactivator $1 \mathrm{a}$; $\mathrm{PGC}-1 \mathrm{~b}$, peroxisome proliferator activated receptor $\mathrm{g}$ coactivator $1 \mathrm{~b}$; PI3K, phosphatidylinositol 3-kinase; PKA, protein kinase A; PKC, protein kinase C; POLG, polymerase gamma, mitochondrial; PRC, PGC-1 a -related coactivator; PTPase, protein tyrosin phosphatase; RCI, respiratory control index; RIP, receptor (TNFRSF)interacting serine-threonine kinase 1; ROS, reactive oxygen species; SMAC/DIABLO, second mitochondria-derived activator of caspases; TBARS, thiobarbituric acid reacting substances; tBid, truncated Bid; TCDCA, taurochenodeoxycholic acid; TDCA, taurodeoxycholic acid; TFAM, mitochondrial transcription factor A; TFB1M, mitochondrial transcription factor B1 (TFB1M); TFB2M, mitochondrial transcription factor B2 (TFB2M); TGF-b, transforming growth factor b; TNF-a, tumor necrosis factor a; TOM, translocase of the outer membrane; TRADD, TNFRSF1A-associated via death domain (TRADD); TRAIL, tumor necrosis factor-related apoptosis-inducing ligand; TRAIL/APO2L, TNF (ligand) superfamily, member 10; TRAIL-R2, TRAIL receptor 2; TUDCA, tauroursodeoxycholic acid; UCP-2, uncoupling protein 2; UDCA, ursodeoxycholic acid; XIAP, X-chromosome linked inhibitor of apoptosis; Dym, mitochondrial membrane potential.

Key Words: Mitochondrial function, Bile acids, Apoptosis, Oxidative stress, Review

Send correspondence to: Juan Sastre, Department of Physiology, School of Pharmacy, University of Valencia, Avda. Vicente Andres Estelles, s/n, 46100 Burjassot, Valencia, Spain, Tel: 34-96-3543815, Fax: 34-96-3543395, E-mail: juan.sastre@uv.es

Figure 1. Bile acids together with death ligands receptors (Fas and TRAIL-R2/DR5) casuse apoptosis in hepatocytes during bile duct ligation. Inflammatory cells promote release of cytokines and death receptors ligands (FasL and TRAIL), which activate proapoptotic caspases, truncation of Bid (tBid) and activation of Bax/Bak. Bile acid accumulation in the cholestatic liver promotes apoptosis by different mechanisms: a) FADD accumulation on the plasma membrane; b) phosphorylation of cFLIP (an anti-apoptotic protein), yielding to an inactive form; c) increase of TRAIL-R2 mRNA, which potentiates the apoptotic stimulus. Nonetheless, bile acids also favor survival of the hepatocyte by activation of NF-kB. Mitochondria, stimulated by bile acids and/or proapototic Bax/Bak, trigger apoptosis. The result is a loss of mitochondrial membrane potential, decrease in ATP synthesis, and increase in ROS production. These mechanisms lead to metabolic alterations, apoptosis, and fibrosis. Abbreviations: BAs, bile acids; HSC, hepatic stellate cells; ROS, reactive oxygen species.

Figure 2. Mitochondrial biogenesis is defective during cholestasis. Renewal of mitochondria is brought about by redox-sensitive NRF-1 and GABP- a, which promote transcription of nuclear encoded-mitochondrial genes. The dehacetylase SIRT1, which participates in the regulation of PGC-1alpha activity, PGC-1a and GABP-a are decreased in the cholestatic liver. PRC and AKT do not cooperatively support NRF-1 activity during cholestasis. In this situation transcription of TFAM, POLG, CYCS, and some ATPase subunits is blunted, and mitochondrial biogenesis is not effective. Long-term cholestasis is characterized by a marked loss of mtDNA and increased frequency of mtDNA deletions. Abbreviations: CYCS, cytochrome c somatic; mtDNA, mitochondrial DNA; POLG, mitochondrial polymerase gamma; TFAM, transcription factor A, mitochondrial.

Running title: ???? 
List of required items

Note: This galley is provided to you for text correction. Please read this galley with great care and make all necessary text changes. Following submission of the first galley, text changes will not be possible without ordering an entire reprocessing step. If required, the form can be obtained at (http://www.bioscience.org/submit.doc).

The following marked items are not provided or formatted according to per FBS style. Please format or provide the item(s) indicated below. Details on proper formatting of the document and instruction for obtaining doi linked references is available at the end of the publication forms.

$\bigotimes$ Text.

Change non-English characters to their English correlates. These characters will appear as blank boxes in the text upon publication

Place references within parenthesis at the end of sentences.

$\bigotimes$ References. Format per FBS style. Do not use automatic numbering of Word for references. All references should be numbered manually. Follow the following style for references. All references must be justified to right and left and there should be hard return between references as follows.

1. Bart Karl, Peter Thomas: Molecular and cellular adaptation of muscle in response to exercise. Physiol Rev 23, 520-535 (1995)

2. Bart Marks, Peter Goll. Skeletal muscle adaptability: significance for metabolism and performance. In: Handbook of Physiology, Sect 10 Skeletal muscle. Eds: LD Peachey, RH Norbert, SR Finn Bethesda, Maryland (1981)

or

1. B Karl, P Thomas: Molecular and cellular adaptation of muscle in response to exercise. Physiol Rev 23, $520-535$ (1995)

2. B Marks, P Goll. Skeletal muscle adaptability: significance for metabolism and performance. In: Handbook of Physiology, Sect 10 Skeletal muscle. Eds: LD Peachey, RH Norbert, SR Finn Bethesda, Maryland (1981)

$\bigotimes$ Tables. No tables

$\triangle$ Running title. Provide a running title less than 55 characters. See sample [Running title: Production and reduction of ROS]

$\bigotimes$ Figures. Provide per FBS style. Figures should be of high quality and $>300$ dpi. Submit as fig1.jpg etc. Do not use any other filename. Do not include filename or any other name or any white or unused spaces around figure. Crop the figure close to the image so that no white space around any figure is visible. Place multipart figures in a single file. Place labels in the left lower corner of each figure. Figures that do not follow the above guidelines can not be used for document processing

$\bigotimes$ DOI linked references provided within a file named doi.doc. All doi linked references must have live links. Do not paste data as text. Paste in native format to maintain the links. Live links will lead to conversion of the cursor to a hand. See sample below. Place cursor over doi:10.1002/ijc.20631 and you will note the cursor changes to a hand. All doi in the ref list must have similar live links. Follow the steps provided below to obtain the doi with live links. Some references may not have doi. Please disregard such results. Such references will be followed by a statement such as [doi not found]. Please do not remove such references from the list.

K Almholt, LR Lund, J Rygaard, BS Nielsen, K Danø, J Rømer, M Johnsen: Reduced metastasis of transgenic mammary cancer in urokinase-deficient mice. Int J Cancer 113 (4), 525-32 (2005).

doi:10.1002/ijc.20631

1. Go to http://www.crossref.org/

2. Click on "simple text query" in the left column of the page

3. Copy about 50 references at a time from the referfence list

4. Paste the references into the query box

5. Click "submit" button

6. The doi linked references will be displayed in about 30 seconds on the screen

7. Copy all the references including those that do not have live doi links by pressing "Control+C"

8. Paste the data into a blank new document

9. Repeat this process for other references

10. Save the file as doi.doc. Do not add any other text to the page (such as DOI references etc)

11. Submit the file with other items including galley, forms, figures, etc to fbs@bioscience.org. 


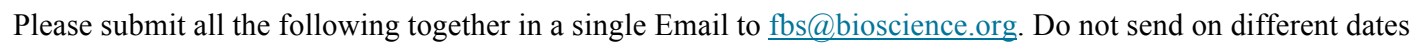

1. Galley (do not change the manuscript number). Sample (1435.doc)

2. Figures. Submit figures as jpg files named fig1, fig2 etc. Do not use any other style such as Fig1 or Fig 1 et.

3. DOI linked references with tabular format and links. Submit as doi.doc (do not use any other filename)

4. Publication forms. Submit as forms.doc (do not use any other filename)

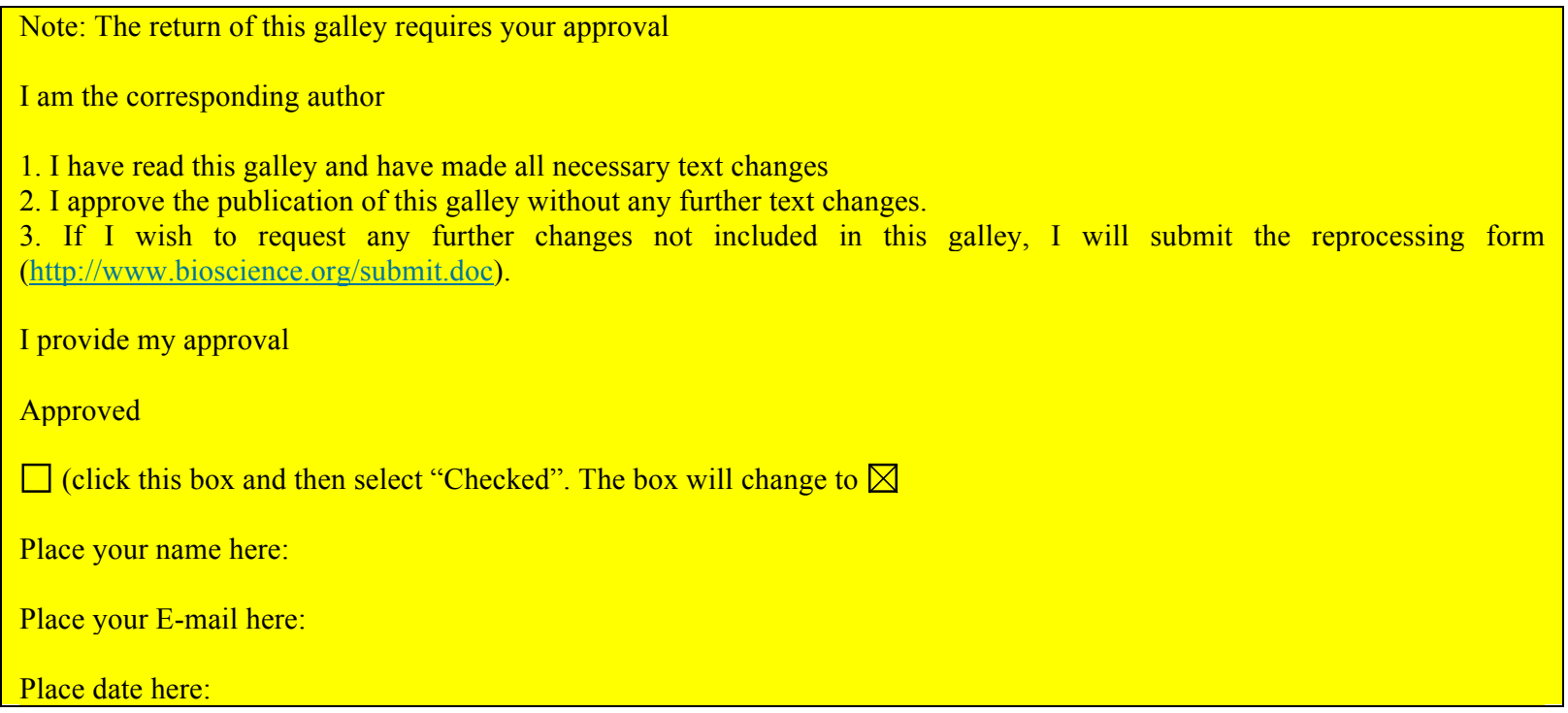

Manuscript Type: Invited review

Managing Editor: Marcelo G. Roma 